\title{
Thermal Performance Enhancement of a Flat Plate Solar Collector Using Hybrid
}

\section{Nanofluid}

\author{
Omar A. Hussein ${ }^{1,2}$, Khairul Habib ${ }^{1 *}$, Ali S.Muhsan ${ }^{3}$, R. Saidur ${ }^{4,5}$, Omer A. Alawi ${ }^{6}$, Thamir K. Ibrahim ${ }^{2}$ \\ ${ }^{1}$ Department of Mechanical Engineering, Universiti Teknologi PETRONAS, 32610 Bandar Seri Iskandar, Perak \\ Darul Ridzuan, Malaysia. \\ ${ }^{2}$ Mechanical Engineering Department, College of Engineering-Alsharkat, Tikrit University, Tikrit, Iraq. \\ ${ }^{3}$ Petroleum Engineering Department, Universiti Teknologi PETRONAS, 32610 Bandar Seri Iskandar, Perak, \\ Malaysia. \\ ${ }^{4}$ Research Centre for Nano-Materials and Energy Technology (RCNMET), School of Science and Technology, \\ Sunway University, Malaysia. \\ ${ }^{5}$ Department of Engineering, Lancaster University, LA1 4YW, United Kingdom \\ ${ }^{6}$ Department of Thermofluids, School of Mechanical Engineering, Universiti Teknologi Malaysia, 81310 UTM \\ Skudai, Johor Bahru, Malaysia \\ Corresponding Author, E-mail address: khairul.habib@utp.edu.my \\ Tel: +60102442375, Fax: +6053656461
}

\begin{abstract}
Covalent Functionalized-Multi wall carbon nanotubes (CF-MWCNTs) and Covalent Functionalized-graphene nanoplatelets (CF-GNPs) with hexagonal boron nitride (h-BN) were suspended in distilled water to prepare the hybrid nanofluids as working fluids inside the Flat Plate Solar Collector (FPSC). Different concentrations of the hybrid nanoparticles were considered at $(0.05 w t \%, 0.08 w t \%$, and $0.1 w t \%)$ and Tween-80 (Tw-80) was used as a surfactant. The stability and thermophysical properties were tested using different measurement tools. The structural and morphological properties were examined via several analyses namelyusing FTIR, XRD, UV-vis spectrometry, HRTEM, FESEM, and EDX. The thermal efficiency of FPSC were tested under different volumetric flow rates $(2 \mathrm{~L} / \mathrm{min}, 3 \mathrm{~L} / \mathrm{min}$, and $4 \mathrm{~L} / \mathrm{min}$ ), whereas the efficiency of the collector was determined based on ASHRAE standard 93-2010. As a result, the most thermalefficient solar collector improved up to $85 \%$ with hybrid nanofluid as the absorption medium at 4 $\mathrm{L} / \mathrm{min}$ flow rate. Increment in nanoparticles' weight percentageconcentrations enhanced thermal energy gain and resulted in higher fluid outlet temperature.
\end{abstract}

Keywords: Flat plate solar collector, hybrid nanofluid, Thermal efficiency, Thermo-physical properties.

${ }^{1}$ Corresponding Author, Tel: +60102442375 , Fax: +60 53656461

E-mail address: khairul.habib@utp.edu.my 


\section{Introduction}

The depletion of fossil fuels, along with escalating global energy demand, has highlighted the importance of alternative energy sources for technological innovations [1]. As such, heating water for both industrial and domestic purposes using solar energy has gained vast popularity, especially using FPSC and solar collectors that comprise of flat plate, and evacuated tube solar collector (ETSC)types. Solar energy has been highly sought and studied due to its availability and clean energy featuressource of energy [2]. Accessible throughout the globe, the use of s Solar energy covers multiple applications, such ascan be applied in generating electricity, air conditioning, and hot water production. Solar radiation, which is leading for water heating systems in both domestic and industrial domains, has been investigated vastly [3] for its cost-effective and straightforward approach. The most vital aspect of the solar energy system refers to collectors that absorb and convert solar radiation to heat for use in working fluids that flow through channels and pipes, as elaborated in detail [4-6]. An issue of this system lies in boosting its thermal performance.

One practical and effective way of enhancing the efficiency of solar collectors is by employing high thermal and conductive working fluids [7-8]. The solar collector has a low-temperature operation that is cost-effective and nen intricate, thus suitable to apply with several-different working fluids [8]. The use of nanofluids has been reported in many studies to improve the functionality of the solar thermal system [9], primarily by increasing the heating and cooling performances of the working fluids.

Synthesizing hybrid nanofluid is essential to gain the synergetic association of properties with other related elementsimprove thermophysical properties and heat transfer performance. For instance, $\mathrm{Al}_{2} \mathrm{O}_{3}-\mathrm{Cu}$ nanofluid, was prepared via hydrogen reduction method using the powder of $\mathrm{Al}_{2} \mathrm{O}_{3}$ and $\mathrm{CuO}$ (ratio, 90:10), resulting in a steeper increase of viscosity than conductivity with 
concentrations [10]. Sander et al. [11] empirically synthesized nanocomposite particles of MWCNT- $-\mathrm{Fe}_{3} \mathrm{O}_{4}$ in a range of concentrations $(0-0.3 \mathrm{vol} \%)$ to assess its thermal properties. performance of the thermal property. Next, Baby and Sundar [12] discovered the improvement of thermal conductivity by $0.08 \%$ at $25{ }^{\circ} \mathrm{C}$ and with $0.04 \%$ volume fraction using Ag/MWCNT-HEG hybrid nanofluids. By using both covalent and non-covalent functionalization techniques to determine the rheological properties of MWCNT-Ag nanocomposite, Amiri et al. [13] reported that the covalent method was more suitable to stabilize the nanofluid thermal attribute. Safi et al. [14], assessed $\mathrm{MWCNT}-\mathrm{TiO}_{2} /$ water hybrid nanofluids in a plate heat exchanger, discovered 20.2\% of heat transfer coefficient increment, when compared to the base fluid. Huang et al. [15] combined $0.0111 \% \mathrm{MWCNT} /$ water nanofluid with $1.89 \% \mathrm{Al}_{2} \mathrm{O}_{3} /$ water nanofluid to examine the efficiency of the plate heat exchanger. Despite the excellent use of MWCNTs nanomaterials to integrate hybrid nanofluids, the demand for graphene nanoplatelets (GNPs) has escalated tremendously [1617]:- This intiatedthus the initiation of a new synthesis technique to produce GNP-Ag-Water nanofluid. In the latest technology for GNP-Pt-Water nanofluid synthesis [18], its dispersion in DW showed a $17.77 \%$ improvement in thermal conductivity at $0.1 \%$ weight concentration and $40^{\circ} \mathrm{C}$. Another study investigated the impacts of particle concentration (range, $0.0 \%-2.3 \%$ ) and temperature (range, $25-50{ }^{\circ} \mathrm{C}$ ) on the thermal conductivity of f-MWCNTs- $\mathrm{Fe}_{3} \mathrm{O}_{4}-\mathrm{EG}$ hybrid nanofluid [19]. The form of covalent nanotubes functionalization in MWCNTs could help in covalent modification of h-BN. The modification of the h-BN with amine functional groups was done within the Zettl group [20] that conferred chemical heads for the attachment of other moieties, thereby yielding hybrid materials with close similarity to the hybrid MWCNT-Pd NPs [21].

There is growing literature regarding the use of hybrid nanofluids in the solar collector and-to improve the efficiency-of hybrid nanofluids. Hence, hybrid nanofluids can enhance thermal 
conductivity at a lower concentration within a range of temperatures. Despite the poor rheological property, CF-GNPs and CF-MWCNTs displayed exceptional thermal conductivity improvement and higher viscosity than those used in isolation as heat transfer working fluids. Industrial sectors are concerned with saving energy by reducing the pumping power apart from enhancing heat transfer. The viscosity of nanoparticles is important parameters that influence pressure drop and friction factor. Thus, the current experiment considered the effect of hybrid nanofluids on increasing pressure drop and friction factor. The influence of hybrid nanofluids with different concentrations on pressure drop and friction factor. Using nanofluids instead of distilled water increases pressure drop. The results reveal that the pressure drop depends on the total nanofluids concentration. and the negative effect of nanoparticles because of the increased concentration of nanofluids. This increase in pressure is due to the rising viscosity and flow rate of nanofluids. MWCNTs, GNPs and h-BN of large nanoparticles that must consider that agglomerations may occur which causes high pressure during the experimental run. The increasing friction factor depends on particle concentration and Reynolds number. Similar results were observed by Sadeghinezhad et al. [22], who revealed that the particle concentration and Reynolds number affect the pressure drop. The sizes of MWCNTs, GNPs and h-BN may increase friction factor because of the effect of the fluid movement and the random movement of such large nanoparticles. This present study synthesized novel hybrid nanocomposite powder via a chemical reaction method. Both GNPs and MWCNTs were given acid treatment and later, decorated with h-BN. Next, nanocomposite materials in DW were dispersed to synthesize the new hybrid nanofluids [23].

The performance of hybrid nanofluids that served as working fluids in FPSC was assessed in this study to determine their benefit in terms of synergetic compatibility. Both CF-GNPs and CF-MWCNTs with high aspect ratio and conductivity were applied to improve the performance 
of single material with h-BN fluid. However, no study has evaluated CF-MWCNTs / CF-GNPs hybrid nanofluids with h-BN on flat plate solar collector (FPSC). Thus, this study examined CFMWCNTs/CF-GNPs with h-BN water-based hybrid nanofluids to improve the thermal performance of FPSC. The production of hybrid nanofluids is elaborated. The previous experimental investigations on the use of nanofluids as working fluids in FPSCs are summarized in Table1.

Table 1. Experimental Investigations on the Use of Nanofluids in FPSCs. 


\begin{tabular}{|c|c|c|c|c|c|c|c|}
\hline Reference & $\begin{array}{c}\text { Baseflui } \\
\text { d }\end{array}$ & Type & $\begin{array}{l}\text { Nanofluid } \\
\text { Size }(n m)\end{array}$ & Concentration & Surfactant & $\begin{array}{c}\text { FPSC } \\
\text { Specifications }\end{array}$ & Findings \\
\hline Natarajan \& Sathish [24] & Water & MWCNT & - & 0.2 to $1.0 \mathrm{vol} \%$ & SDS & - & $\begin{array}{l}\text { At } 1.0 \text { vol } \% \text {, thermal conductivity } \\
\text { increased by } 41 \% \text {. }\end{array}$ \\
\hline Yousefi et al. [25] & Water & MWCNT & $10-30$ & $0.2 \mathrm{wt} \%$ & Triton X-100 & $2 \mathrm{~m}^{2}$ & $\begin{array}{l}\text { Increased efficiency with the increase in } \\
\text { nanofluid stability. }\end{array}$ \\
\hline Vijayakumaar et al. [26] & Water & SWCNTs & 1 & $\begin{array}{c}0.40,0.50 \text { and } 0.60 \\
\text { wt } \%\end{array}$ & Polysorbate 80 & $0.74 \times 0.485 \mathrm{~m}$ & $\begin{array}{l}\text { At } 0.5 \mathrm{wt} \% \text {, the increase in FPSC's } \\
\text { performance was close to that of using } \\
\text { MWCNT. }\end{array}$ \\
\hline Said et al. [27] & Water & $\mathrm{TiO}_{2}$ & $20-40 \mathrm{~nm}$ & 0.1 and 0.3 vol $\%$ & PEG 400 & $1.84 \mathrm{~m}^{2}$ & $\begin{array}{l}\text { Collector's energy efficiency presented is } \\
\text { lower than that obtained using carbon } \\
\text { nanostructure-based nanofluids. }\end{array}$ \\
\hline Said et al. [28] & Water & SWCNTs & $\begin{array}{l}\mathrm{L}=1-3 \\
\mu \mathrm{m}, \mathrm{D}= \\
1-2 \mathrm{~nm}\end{array}$ & 0.1 and 0.3 vol $\%$ & SDS & $1.84 \mathrm{~m}^{2}$ & $\begin{array}{l}\text { Energy and exergy efficiencies reached } \\
95.12 \% \text { and } 26.25 \% \text {, while water was } \\
42.07 \% \text { and } 8.77 \% \text {, respectively. }\end{array}$ \\
\hline Michael \& Iniyan[29] & Water & $\mathrm{CuO}$ & $\begin{array}{l}0.3 \text { and } \\
0.21 \mathrm{~nm}\end{array}$ & 0.05 vol\% & SDBS & $2.08 \times 1.05 \mathrm{~m}$ & $\begin{array}{l}\text { A maximum increase of } 6.3 \% \text { in } \\
\text { collector's efficiency. }\end{array}$ \\
\hline Ahmadi et al. [30] & Water & GNPs & - & 0.01 and $0.02 \mathrm{wt} \%$ & - & $0.47 \times 0.27 \mathrm{~m}$ & $\begin{array}{l}\text { Efficiency enhanced with the GNPs/water } \\
\text { up to } 12.19 \% \text { for } 0.01 \text {-wt } \% \text { and } 18.87 \% \\
\text { for } 0.02 \text {-wt } \% \text {. }\end{array}$ \\
\hline Verma et al. [31] & Water & $\mathrm{MgO}$ & $40 \mathrm{~nm}$ & $\begin{array}{l}0.25,0.5,0.75 \\
1.0,1.25, \text { and } 1.5 \\
\text { vol } \%\end{array}$ & CTAB & $75 \times 50 \mathrm{~cm}$ & $\begin{array}{l}\text { Efficiency of } \mathrm{MgO} \text {-Water was lower than } \\
\text { carbon nanostructured. }\end{array}$ \\
\hline Verma et al. [32] & Water & $\begin{array}{l}\text { Metallic } \\
\text { oxides, }\end{array}$ & - & $\begin{array}{l}0.25,0.5,0.75 \\
1.0,1.5, \text { and } 2.0 \\
\text { vol } \%\end{array}$ & Triton X-100 & $75 \times 50 \mathrm{~cm}$ & $\begin{array}{l}\text { The sequence of efficiency was MWCNT } \\
>\text { Graphene }>\mathrm{CuO}>\mathrm{Al}_{2} \mathrm{O}_{3}>\mathrm{TiO}_{2}>\mathrm{SiO}_{2}\end{array}$ \\
\hline
\end{tabular}




\begin{tabular}{|c|c|c|c|c|c|c|}
\hline & & Graphene, & & & & with, $16.97 \%, 12.64 \%, 8.28 \%, 5.09 \%$, and \\
\hline Pressent Work & Water & $\begin{array}{c}\text { h-BN, } \\
\text { Graphene } \\
\text { nanoplatelets } \\
\text {, MWCNTs }\end{array}$ & $\begin{array}{c}\mathbf{0 . 0 5 ,} 0.08 \text { and } 0.1 \\
\text { wt } \%\end{array}$ & Tween-80 & $\begin{array}{c}1,988 \times 1,041 \times \\
90 \mathrm{~mm}\end{array}$ & $\begin{array}{l}\text { Efficiency enhanced with the hybrid } \\
\text { nanofluid up to } 11.8 \% \text { for } 0.05 \text { wt } \% \\
\text { and } 21.9 \% \text { for } 0.10 \mathrm{wt} \% \text {. }\end{array}$ \\
\hline
\end{tabular}




\section{Experimental method}

\subsection{Nanofluid preparation}

The pristine MWCNTs (with a diameter of $15 \mathrm{~nm}$, length of $5 \mu \mathrm{m}$ with a purity of $95 \%$ ) and GNPs (with a purity of $98 \%$, maximum particle diameter of $2 \mu \mathrm{m}$ and SSA $750 \mathrm{~m}^{2} / \mathrm{g}$ ) were purchased from, (XG Sciences, Lansing, MI, USA). Sulfuric acid $\left(\mathrm{H}_{2} \mathrm{SO}_{4}, 95-97 \%\right)$ and nitric acid $\left(\mathrm{HNO}_{3}\right.$, $65 \%$ ) were used as the functionalization media. Nanoparticles of $\mathrm{h}$ Hexagonal boron nitride (h-BN) nanoparticles (purity more than 99\%) are a white slippery solid with a layered structure that-was purchased from Sigma-Aldrich Co., Selangor, Malaysia.

Pristine MWCNTs and GNPs are hydrophobic material and it cannot be dispersed in any solvent which is polar like distilled water. The suitable way to make MWCNTs and GNPs hydrophilic is by introducing functional groups of carboxyl (-COOH) and hydroxyl $(-\mathrm{OH})$ on its surface via acid treatment, this process also known as functionalization process, as shown in Fig. (1). This process was achieved by dispersing pristine MWCNTs and GNPs in a solution of $\mathrm{H}_{2} \mathrm{SO}_{4}$ and $\mathrm{HNO}_{3}$ at a ratio of (3:1) (active acid medium) through three steps. We used sulfuric acid to nitric acidthis ratio of 3:1-because this -it is the suitable ratio for acid treatment[33]. In the first step, the pristine MWCNTs and GNPs were added into the $\mathrm{H}_{2} \mathrm{SO}_{4}$ solution and mixed properly using a magnetic stirrer for 30 minutes. In the second step, $\mathrm{HNO}_{3}$ was gradually added to the mixture while the mixture container was placed in an ice bath to control the reaction temperature and avoid solution evaporation. The mixture solution was then stirred for $30 \mathrm{~min}$, followed by three hours in the ultrasonication bath at $\left(60^{\circ} \mathrm{C}\right)$. In the final step, CF-MWCNTs and $\mathrm{CF}-\mathrm{GNPs}$ were collected and washed thoroughly five times with distilled water. then-Then, it was centrifuged at $6000 \mathrm{rpm}$ for 15 min to remove excess acid and then dried under drying oven for $24 \mathrm{~h}$ at $80^{\circ} \mathrm{C}$. Samples with different concentrations of CF-MWCNTs and CF-GNPs $(0.1 \mathrm{wt} \%)$ were prepared by adding the 
CF-MWNTs and CF-GNPs into distilled water and mix them properly using a probe sonicator for 60 minutes.

\subsection{Synthesis of hybrid Nanocomposite}

The required nanofluids (20\%CF-MWCNTs+20\%CF-GNPs with $60 \%$ h-BN)/water), both at the ratio of 40:60\% in $0.1 \mathrm{wt} \%$ were prepared using a two-step approach. The mixture solution-was then stirred for $30 \mathrm{~min}$, followed by two hours in an ultrasonic bath at $60^{\circ} \mathrm{C}$ before stirring for 30 minutes and further sonication at $750 \pm 50 \mathrm{~Hz}$ for one hour. The hybrid nanofluids were prepared at different concentrations $(0.05,0.08, \& 0.1$ wt.\%). The highest concentrations of CFMWCNTs/Water \& CF-GNPs/Water were first prepared in DW before adding the required quantities of h-BN \& Tween-80 into the solution in the second step. The solution was placed in a stainless steel autoclave for $3 \mathrm{~h}$ at $140^{\circ} \mathrm{C}$. After the reactions were washed several times with distilled water thoroughly to remove excess acid and then dried under drying oven. The optimum concentration of Tween-80 in the prepared nanofluid was determined by observing for the stability, foaming and aggregation of the nanofluids containing different constituent concentrations. A Tween-80 ratio of (1:1) was chosen for the study. The new hybrid nanofluids showed good stability and uniformity without any sedimentation observed by the naked eye. Fig. ( 1 - $)$ shows the schematic of the molecular structure of the synthesized new nanocomposite. The container was regularly cooled to prevent the evaporation of the surface-active agent during the preparation of the

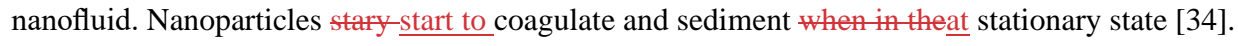

$\emptyset \times 100=\frac{\left[W_{\text {particle }} / \rho_{\text {particle }}\right]}{\left[W_{\text {particle }} / \rho_{\text {particle }}\right]+\left[W_{\text {fluid }} / \rho_{\text {fluid }}\right]}$ 


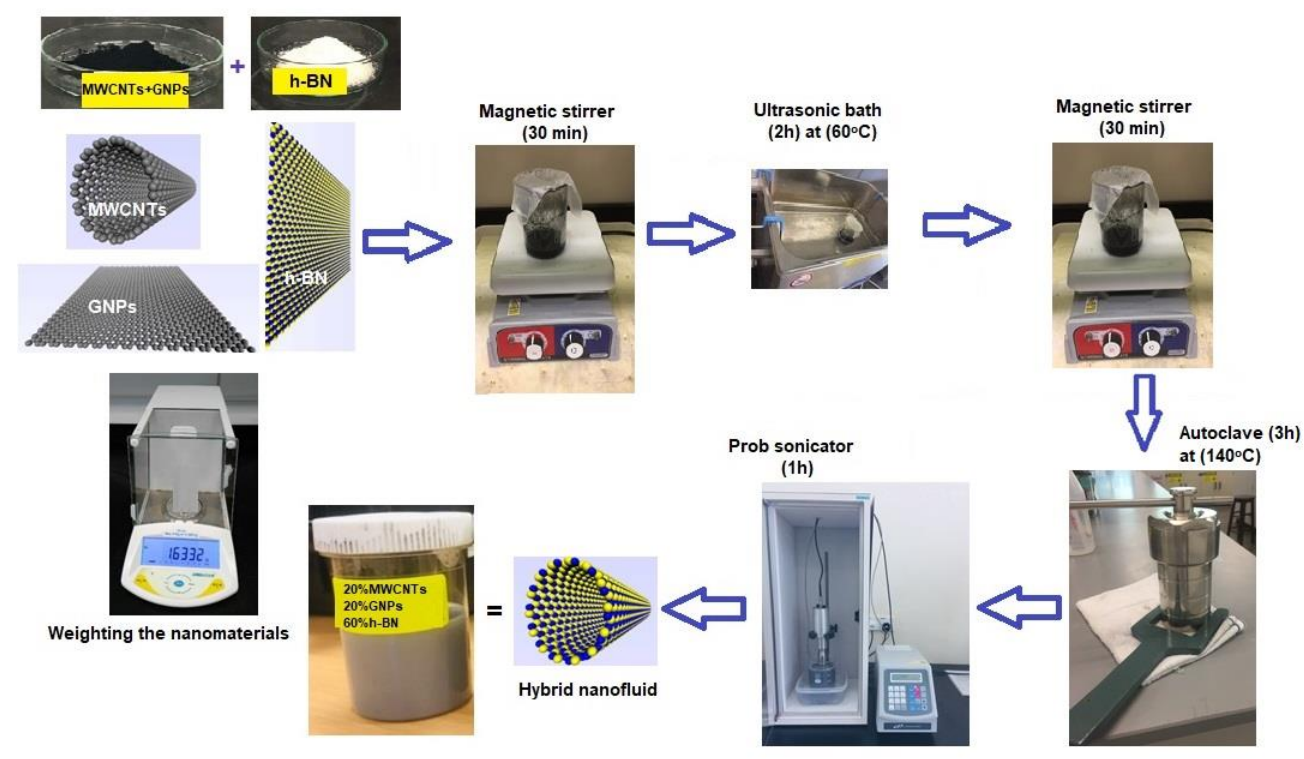

Fig. 1. Schematic of the synthesis of (CF-MWCNTs+CF-GNPS with h-BN) nanocomposite.

\subsection{Experimental techniques}

\subsubsection{Evaluation of stability}

Analysis of-Ultraviolet-Visible spectrophotometry (UV-vis) was used to assess the stability of dispersions of hybrid nanofluids. The measurement of light absorbance of a suspension by UV-vis spectroscopy can be used to make available a quantifiable characterization of the stability. The use of-UV-vis is-was Lambda-operateding in the range of 190-3300 nm wavelengths seurce:with tungsten lamp and deuterium lamps. Spectral bandwidth was with $\div 0.05 \mathrm{~nm}$ to $5 \mathrm{~nm} \mathrm{UV-Vis,} 0.2 \mathrm{~nm}$ to 20nm NIR, (750UV-Vis/NIR, Lambda Company, U.S.A.). Light absorbance was measured by special quartz cuvettes suitable for the UV region since all samples were at certain time intervals 
for an-extra 30 days. A 1:20 ratio diluted in distilled water to allow proper light transmission for all samples.

\subsubsection{Morphology}

The main structure of hybrid nanofluids were analyzed using Fourier transform infrared (FTIR) spectroscopy, High-Resolution Transmission Electron Microscope (HRTEM, HT 7700, Hitachi) and Field Emission Scanning Electron Microscopy (FESEM, SU8000, Hitachi). The HRTEM samples were prepared by sonicating the CF-MWCNTs, CF-GNPs and hybrid nanofluids for 15 minutes in deionized water. Then we put a drop of each sample on a lacey carbon grid a drop of each sample. The evaluation of the FTIR spectra within a wavenumber range of $400-4000 \mathrm{~cm}^{-1}$. Phase compositions were determined by using an X-ray diffractometer (XRD, EMPYREAN, PANALYTICAL) with $\mathrm{Cu}-\mathrm{K} \alpha$ radiation over a $2 \theta$ range from $20^{\circ}$ to $80^{\circ}$. The "PANalytical X'Pert HighScore" software was employed to compare the XRD profiles with the standards compiled by the Joint Committee on Powder Diffraction and Standards (JCPDS).

\subsubsection{Measurement of thermophysical properties}

Determine a $\underline{A}$ shear rate was controlled by Anton Paar rotational rheometer (Model Physica MCR 301, Anton Paar GmbH Ltd, Malvern, UK) and use the double gap DG 26.7 was used for steadyshear rheological properties of water and water-based hybrid nanofluids. The temperatures and concentrations were in the ranges of $\left(20-60^{\circ} \mathrm{C}\right)$ and $(0.05-0.1 \mathrm{wt} \%)$ were used. To determine a thermal conductivity ${ }_{2}$ by the thermal property's analyzer device KD2 Pro (Decagon Devices, Inc., USA) was used, the prepared nanofluids were measured-with an accuracy of approximately 5\%. A $1.4 \mathrm{~kW}$ water bath WNB22 Memmert (Germany) was used to keep the samples at the preferred 
temperature during measurements and-with $0.1{ }^{\circ} \mathrm{C}$ accuracy. Specific heat capacities of the base fluids and the hybrid nanofluids were measured with a differential scanning calorimeter (DSC 8000, Perkin Elmer, USA) with an accuracy of $\pm 1.0 \%$.

\subsection{Experimental setup}

The experimental set up was designed to be a standard and commercialized solar water heater using FPSC with minor installation modifications to meet the study objectives. The test rig was assembled in the solar site-Solar Thermal Advanced Research Centre [STARC] of at the University Teknologi PETRONAS located on $101^{\circ}$ east longitude, $4.38^{\circ}$ north latitude, and altitude of $32 \mathrm{~m}$ above sea level. The test rig refers to an automatic water heating system using solar energy to heat water from 50 to $70^{\circ} \mathrm{C}$ (average daily) for storage in a hot water storage tank. To control and increase the temperature of the hot water, electrical immersion heaters were installed for backup heating (see Fig. 2). The back view of the configuration in Fig. 2 (a) displays the main components installed on the platform, including FPSC, pump station, expansion tank, storage tank, air vent, hand pump, and solar meter. Fig. 2 (b) exhibits the front view of the prepared test rig, inclusive of the controller, dc power supply, data logger-home, anemometer, and pyranometer. The schematic of the linear system diagram is illustrated in Fig. (-3). 

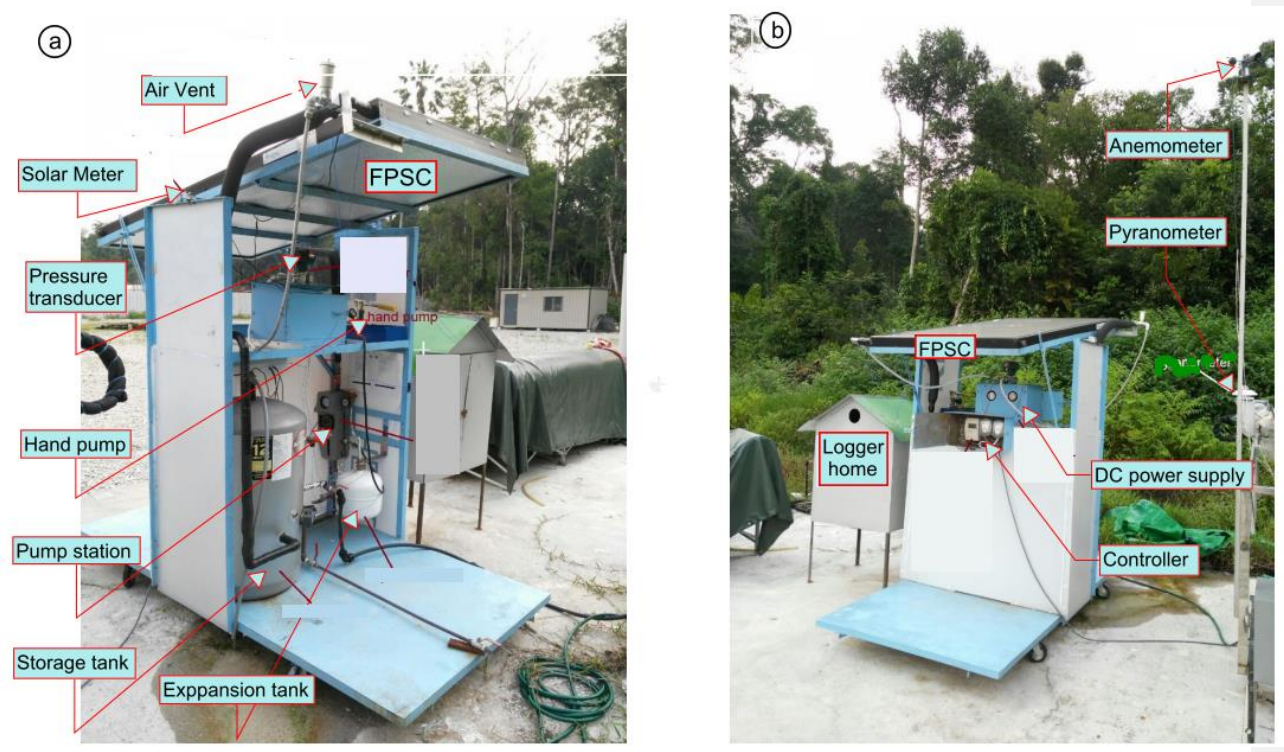

Fig. 2. Photograph of the final installation situation of the experimental set up in the solar site [STARC] (a) back views with main components, (b) front view sight with the controller.

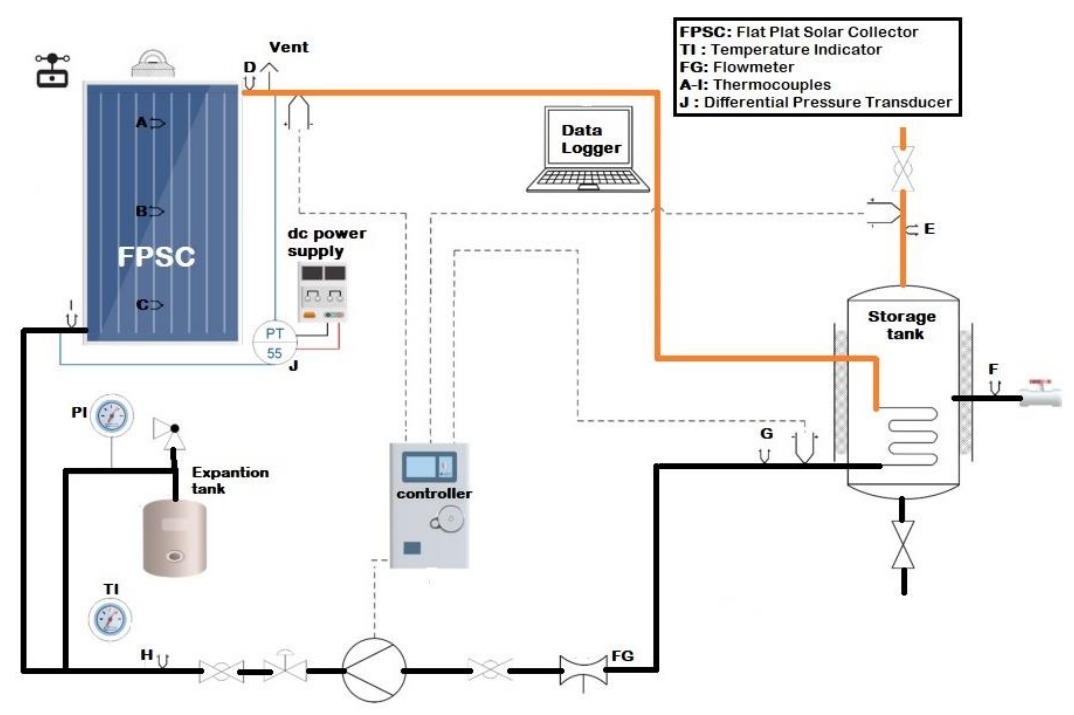

Fig. 3. Schematic sketch of the experimental setup. 


\subsubsection{Flat-Plate Solar Collector Section}

An FPSC with aluminium case and mineral rock wool water-resistant insulation is provided for the test rig. The collector glass is a transparent cover sealed in the collector frame with EPDM rubber material. The detailed specification of the FPSC is given in Table $(2)$.

Table 2. Technical specifications of the FPSC setup.

\begin{tabular}{|c|c|c|}
\hline Details of parameters & Specification & Unit \\
\hline Dimensions & $1,988 \times 1,041 \times 90$ & $\mathrm{~mm}$ \\
\hline Casing mAaterial & $\begin{array}{c}\text { Electrostatically pPainted } \\
\text { (Black) }\end{array}$ & -- \\
\hline Weight & 37.2 & $\mathrm{~kg}$ \\
\hline Sealing Materialmaterial & $\begin{array}{c}\text { Electrostatically Painted } \\
\text { painted (Black) Aluminium } \\
\text { aluminium Casecase }\end{array}$ & -- \\
\hline Gross Areaarea & 2.07 & $\mathrm{~m}^{2}$ \\
\hline Aperture Areaarea & 1.92 & $\mathrm{~m}^{2}$ \\
\hline Absorber Areaarea & 1.89 & $\mathrm{~m}^{2}$ \\
\hline Absorber Materialaaterial & $\begin{array}{l}\text { Almeco Tinex-tinox Highly } \\
\text { highly Selective-selective } \\
\text { Aluminiumaluminium }\end{array}$ & -- \\
\hline Absorptance $(\%)$ & 95 & -- \\
\hline Emittance $(\%)$ & 3 & -- \\
\hline Welding Methodmethod & Laser Weldingwelding & -- \\
\hline Heat Carrier carrier Volumevolume & 1.07 & Litres \\
\hline Number of Riser riser Tubestubes & 10 & -- \\
\hline Tube Pitehpitch & 110 & $\mathrm{~mm}$ \\
\hline Glass Materialmaterial & Low Iron Tempered Glass & -- \\
\hline Transmittance of Glassglass & $91 \%$ & -- \\
\hline Thickness of Glassglass & 4 & $\mathrm{~mm}$ \\
\hline Insulation Materialgaterial & Rockwool & -- \\
\hline Thickness of Woolwool & 50 & $\mathrm{~mm}$ \\
\hline Base Sheetingsheeting & $\begin{array}{l}\text { Embossed Aluminium } \\
\text { aluminium Sheetsheet }\end{array}$ & -- \\
\hline $\begin{array}{l}\text { Max. Operating operating } \\
\text { Pressurepressure }\end{array}$ & 10 bar & -- \\
\hline Max. Collectors-collectors in Seriesseries & 8 & -- \\
\hline $\begin{array}{l}\text { Stagnation Temperature temperature at } \\
1,000 \mathrm{~W} / \mathrm{m} \text { and } 30^{\circ} \mathrm{C}\end{array}$ & 203 & ${ }^{\circ} \mathrm{C}$ \\
\hline
\end{tabular}




\subsubsection{Filling the Solar Loop Section}

There are provided $\mathbf{f} \underline{F}$ ush and fill connections are provided to charge and pressurize the solar circuit using a hand pump and drain the system when it is required. The recommended system pressure is 1.0 bar +0.1 bar per meter static height of FPSC. The collector should not be left exposed to solar radiation when the solar loop and manifolds have been drained. Collectors exposed to a dry state must be covered to prevent possible long- term damage. Furthermore, FPSC should be installed, drained, or refilled at a time when there is shallow light such as late afternoon or early morning.

\subsection{Efficiency calculations}

This section presents the estimates employed to predict the performance parameters of an FPSC performance parameters. The efficiency of the instantaneous collector in light of useful energy to total radiation on the surface of the collector is given in Eqs. (2) and (4), as prescribed in Duffie [35]:

$$
\eta_{i}=\frac{Q_{u}}{A c \cdot G_{t}}
$$

$Q_{u}=\dot{m} C_{p}\left(T_{\text {out }}-T_{\text {in }}\right)$

$\eta_{i}=F_{R}(\tau \alpha)-F_{R} U_{L} \frac{\left(T_{i n}-T_{a}\right)}{G_{t}}$

The heat removal factor, $F_{R}$, is expressed by Eq. (5) as

$F_{R}=\frac{m \cdot C_{p}\left(T_{o u t}-T_{\text {in }}\right)}{A_{c}\left[S-U_{L}\left(T_{\text {in }}-T_{a}\right)\right]}$

\subsection{Uncertainty analysis}

Based on the ASME guidelines[36], an accurate exact measurement was-can not be realized, and several errors were noted on the experimental measurements. The errors were due to calibration 
and data recording (systematic errors), as well as data fluctuations as a result of unsuitable instruments (random errors). The uncertainty of measurements outcomes was estimated to determine the deviation in both experimental parameters and measurements accuracy. Based on Eq. (2), errors of measurements for flow rate, temperature, and solar radiation emerged as the primary sources of uncertainty while assessing the nanofluid-based FPSC. The general form of the equation for uncertainty analysis is given in [37]:

$U_{y}^{2}=\sum_{i=1}^{n} U_{x i}^{2}$

Where $\mathrm{U}_{\mathrm{y}}$ is the total uncertainty of the calculated parameter, while $\mathrm{U}_{\mathrm{xi}}$ is the root sum square (RSS) of the scatter and the measurement uncertainty of each measured parameter. The combined uncertainty for the evaluation of collector efficiency, $U_{\eta 1}$, was determined by the RSS method, as follows [38]:

$U_{\eta_{i}}=\sqrt{\left(\frac{\Delta \dot{m}}{\dot{m}}\right)^{2}+\left(\frac{\Delta\left(T_{\text {out }}-T_{\text {in }}\right)}{T_{\text {out }}-T_{\text {in }}}\right)^{2}+\left(\frac{\Delta G_{t}}{G_{t}}\right)^{2}}$

The errors in $C_{p}$ and $A_{c}$ were assumed as negligible. A similar relation was applied to the measurement of the thermophysical properties of the nanofluids. The specifications and the accuracy of the measuring instruments and sensors used in the present experimental setup are presented in Table $(3)$.

Table 3. Specifications and errors of the measuring instruments used in the present experiment.

\begin{tabular}{|l|l|c|c|c|}
\hline $\begin{array}{l}\text { Measured } \\
\text { parameter }\end{array}$ & \multicolumn{1}{|c|}{ Instrument and sensor type } & Operating & Accuracy & $\begin{array}{c}\text { Maximum } \\
\text { Error }\end{array}$ \\
\hline Surface temperature & Type K thermocouple & $0-1200^{\circ} \mathrm{C}$ & $\pm 0.4 \%$ & $4.8^{\circ} \mathrm{C}$ \\
\hline Data logger & Type K thermocouple & $0-1200^{\circ} \mathrm{C}$ & $\pm 0.8 \%$ & $9.6^{\circ} \mathrm{C}$ \\
\hline Fluid flow rate & $\begin{array}{l}\text { Electromagnetic Flow-flow } \\
\text { Aetermeter }\end{array}$ & $0-10 \mathrm{~kg} / \mathrm{s}$ & $\pm 0.5 \%$ & $0.05 \mathrm{~kg} / \mathrm{s}$ \\
\hline Fluid pressure drop & $\begin{array}{l}\text { Differential Pressure pressure } \\
\text { Transmitter-transmitter }\end{array}$ & $0-25 \mathrm{kPa}$ & $\pm 0.3 \%$ & $\pm 0.075 \%$ \\
\hline $\begin{array}{l}\text { Solar } \\
\text { Radiationradiation }\end{array}$ & KIMO solarimeter SL200 & $1,300 \mathrm{~W} / \mathrm{m}^{2}$ & $\pm 5 \%$ & $65 \mathrm{~W} / \mathrm{m}^{2}$ \\
\hline
\end{tabular}




\section{Results and discussion}

3.1 Characterization of hybrid nanofluids

\subsubsection{XRD diffraction}

Fig. (4) illustrates the XRD patterns of CF-MWCNTs, CF-GNPs, and new hybrid nanofluids. The two peaks at $27.0^{\circ}$ and $42.0^{\circ}$ reflect CF-MWCNTs, while the other diffraction peaks $\underline{\text { at }} 44.0^{\circ}$ and $53.5^{\circ} \rightarrow$ are attributable to the planes of hexagonal graphite structure displayed in Figs. 4(a) and (b) [42]. In this work, XRD was performed on the samples of (CF-MWCNTs and CF-GNPs with h$\mathrm{BN})$ to investigate the chemical effects of the functionalization process on the final product. Fig. (4) shows the XRD patterns of CF-MWCNTs, CF-GNPs, and hybrid nanofluids after functionalization process For for MWCNTs $_{-;}$Ggenerally, the peak associated with the (002) diffraction is located at $2 \theta=27.0^{\circ}, 2 \theta=42.0^{\circ}$ [40]. The broad peaks in Fig. (4b) portrayed a higher intensity than those in Fig. (4a), signifying that CF-GNPs was smaller than CF-MWCNTs [43]. In Fig. (4c) shows the diffraction peaks of both CF-MWCNTs and CF-GNPs with h-BN. The primary dominant peaks for h-BN were noted at 2 Theta $=12.2^{\circ}, 22.0^{\circ}, 25^{\circ}, 26.5^{\circ}, 48^{\circ}, 56^{\circ}$ and $63^{\circ}[41]$. This proved successful oxidation occurred during functionalization processes of MWCNTs that created the functional group $(-\mathrm{COOH})$ on the MWCNTs sidewall, and GNPs sheets which in turn enhanced the interaction between CF-MWCNTs, CF-GNPs particles and made strong bonds with the h-BN matrix. In other words, the oxygen $\theta$ f thein - $\mathrm{COOH}$ group could either promotes electron exchange between h-BN and carbon atoms, or directly interacts with h-BN. and, thus, $\underline{\text { This }}$ played a key role of bonding between the h-BN and the CF-MWCNTs, CF-GNPs surfaces [42]. It can also be seen that there was no carbide formation aken-took place between h-BN and the CF- 
MWCNTs, CF-GNPs after functionalization process. These results were agreed with the previousews studies reported on the same composite [43, 44].

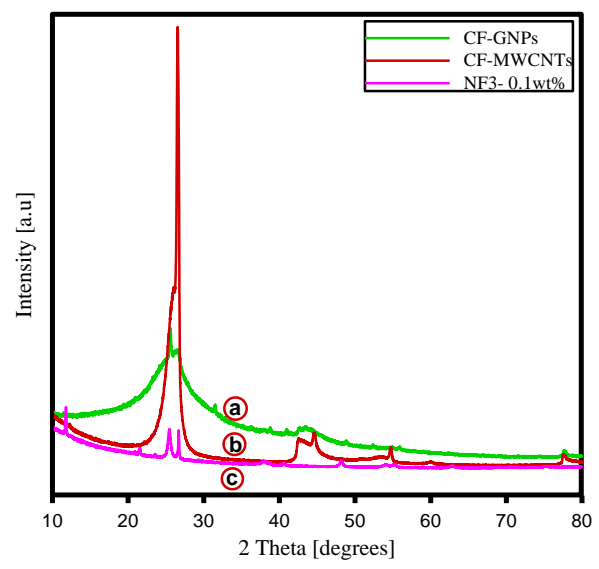

Fig. 4. X-ray diffraction of (a) CF-GNPs (b) CF-MWCNTs (c) Hybrid nanofluids

\subsubsection{Morphology and phase structures of nanostructures}

The HRTEM output in Fig. 5(a-b) shows that in dissolved solutions showed that, the diameter of tangled MWCNT was $24 \mathrm{~nm}$, while CF-MWCNTs, CF-GNPs did not exhibit significant change when compared to MWCNTs and GNPs (see Fig. 5b). Thus, functionalization in a harsh and severe empirical setting failed to affect the structure of the nanotube [45]. The more visible bright patches noted on CF-MWCNTs, CF-GNPs than MWCNTs and GNPs indicate that functionalization generated defective sites and polar groups, namely carbonyl, carboxyl, and hydroxyl groups (see Fig. 6); suggesting the interaction via hydrogen bonding with h-BN nanoparticles [38-39]. The uniform distribution of h-BN attachment on the CF-MWCNTs and CF-GNPs can be noticed in the 
FESEM image (Figs. 5c \& d) illustrate that both CF-GNPs and CF-MWCNTs had been decorated with h-BN nanoparticles. These results were further proved by Energy Dispersive X-ray spectroscopy (EDX). EDX results in Fig. 5(e), show that the EDX measurements portray five components present in hybrid nanofluid; C, Ti, B, N and oxygen. However, Fig. 5(e) shows the chemical composition of samples obtained by EDX analysis from the area displayed. EDX results (presented in Table 4) after acid treatment for CF-MWCNTs, CF-GNPs, and hybrid NF3 the analysis shows the qualitative presence of $\mathrm{B}, \mathrm{O}, \mathrm{Ti}, \mathrm{N}$ and $\mathrm{C}$ as the main elements in nanopowder.
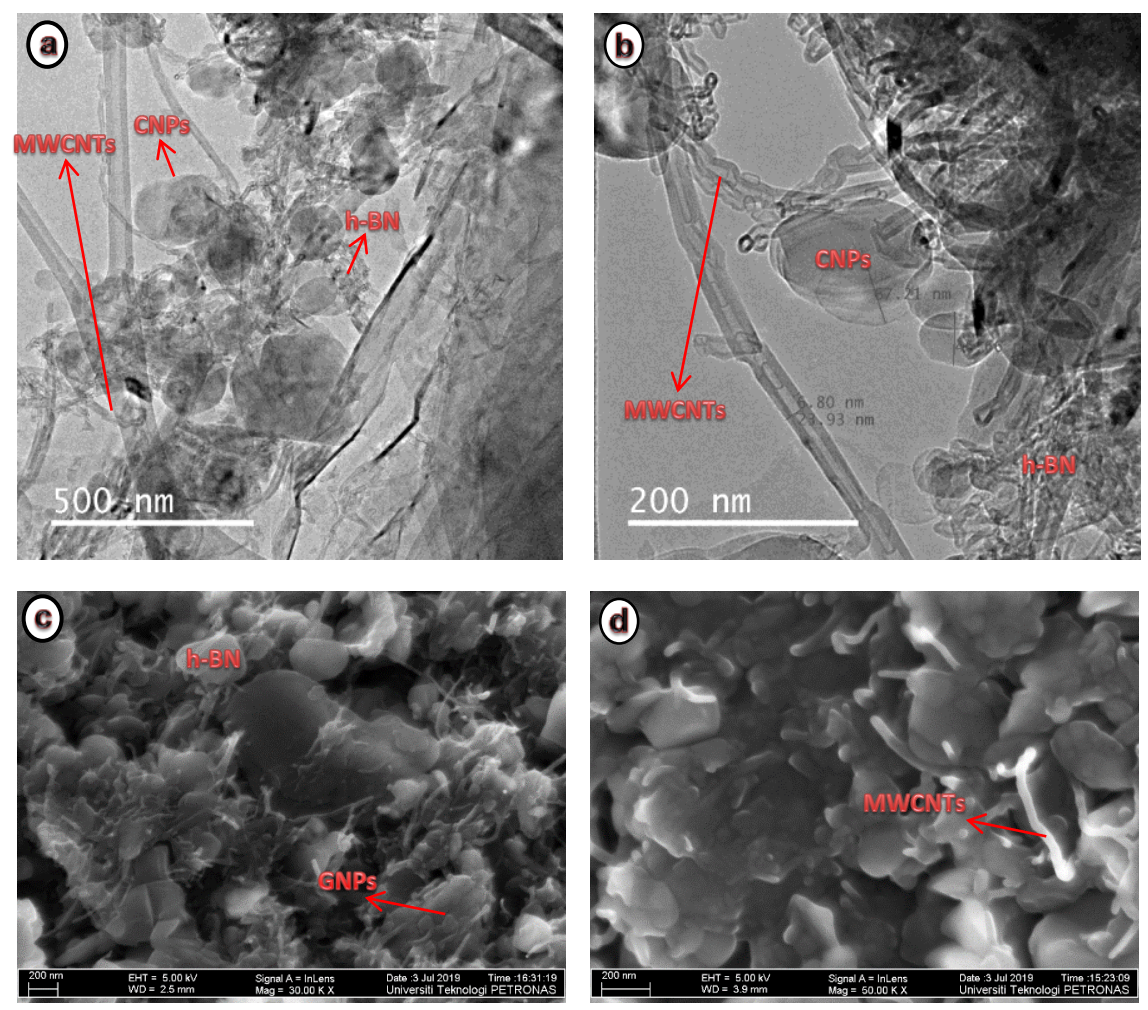


\begin{tabular}{|l|l|l|}
\hline Element & Weight\% & Atomic\% \\
\hline \hline $\mathrm{B} \mathrm{K}$ & 28.56 & 32.34 \\
\hline \hline $\mathrm{C} \mathrm{K}$ & 43.24 & 44.08 \\
\hline $\mathrm{N} \mathrm{K}$ & 20.02 & 17.50 \\
\hline $\mathrm{O} \mathrm{K}$ & 7.82 & 5.99 \\
\hline Ti K & 0.36 & 0.09 \\
\hline \hline Totals & 100.00 \\
\hline
\end{tabular}

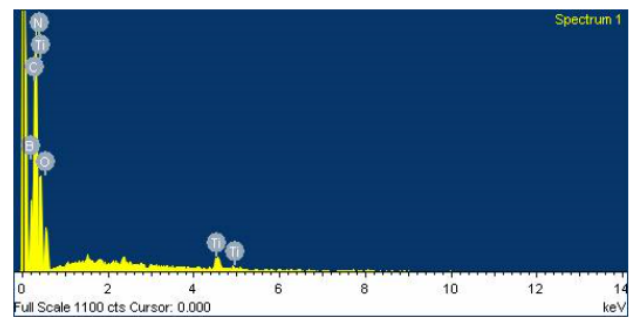

Fig. 5. HRTEM photograph of (a-b), FESEM (c-d) and EDX (e) images of hybrid NF3.

Table 4. EDX results of hybrid NF3.

\begin{tabular}{|c|c|c|}
\hline Element & Weight \% & Atomic \% \\
\hline $\mathrm{C}$ & CF-MWCNTs & 93.70 \\
\hline $\mathrm{O}$ & 9.22 & 6.30 \\
\hline & CF-GNPs & \\
\hline $\mathrm{C}$ & 48.65 & 58.99 \\
\hline $\mathrm{O}$ & 38.72 & 35.25 \\
\hline $\mathrm{Si}$ & 0.24 & 0.13 \\
\hline $\mathrm{S}$ & 12.40 & 5.63 \\
\hline & Hybrid NF3 & 44.08 \\
\hline $\mathrm{C}$ & 43.24 & 5.99 \\
\hline $\mathrm{O}$ & 7.82 & 0.09 \\
\hline $\mathrm{Ti}$ & 0.36 & 17.50 \\
\hline $\mathrm{N}$ & 20.02 & 32.34 \\
\hline $\mathrm{B}$ & 28.56 & \\
\hline
\end{tabular}




\subsubsection{FTIR Spectroscopy}

Fig. (6) illustrates the outcomes of FTIR spectroscopic analysis performed on CF-MWCNTs, CFGNPs, and hybrid_nanaofluids. Bands noted at $1100 \mathrm{~cm}^{-1}$ are attributable to $\mathrm{C}-\mathrm{C}$ bonds and C-O stretching vibration from lactone or phenol groups [44], while at $\sim 1600 \mathrm{~cm}^{-1}$ [45]. Peaks ranging between 3400 and $3460 \mathrm{~cm}^{-1}$ reflected correspondence with -OH groups to signify either adsorption of atmospheric water at FTIR or presence of hydroxyl groups on the material surface [46]. These peaks appeared sharper in CF-MWCNTs and CF-GNPs, mainly because varied functional groups were embedded on the surfaces via functionalization [43]. Peaks with higher intensity for hybrid (3400-3460 $\mathrm{cm}^{-1}$ ), when compared to those for CF-MWCNTs and CF-GNPs, may reflect the h-BN positioned at CF-MWCNTs and CF-GNPs sidewalls via hydrogen bond that occurred between carboxyl groups and h-BN-OH [47]. The dual peaks noted at 2920 and $2850 \mathrm{~cm}^{-}$ ${ }^{1}$ were attributable to $\mathrm{C}-\mathrm{H}$ stretch vibration that turned weak, indicating decoration of $\mathrm{CF}$ MWCNTs and CF-GNPs surfaces with h-BN (see Fig. 6c) [43]. The adsorption peaks for CFMWCNTs and CF-GNPs at $1700 \mathrm{~cm}^{-1}$ signified $\mathrm{C}=\mathrm{O}$ stretching vibration from $-\mathrm{COOH}$. The peak ascribed to $\mathrm{C}=\mathrm{O}$ stretching vibration for hybrid shifted to 1700 from $1650 \mathrm{~cm}^{-1}$. This shows the interaction of h-BN with carboxylic acid groups derived from CF-MWCNTs and CF-GNPs generated chemical bond via esterification [44]. Fig. $(6(\mathrm{c}))$ shows that the adsorption band at $650 \mathrm{~cm}^{-1}$ is ascribed to h-BN-O band vibrational property due to the presence of h-BN [44]. 


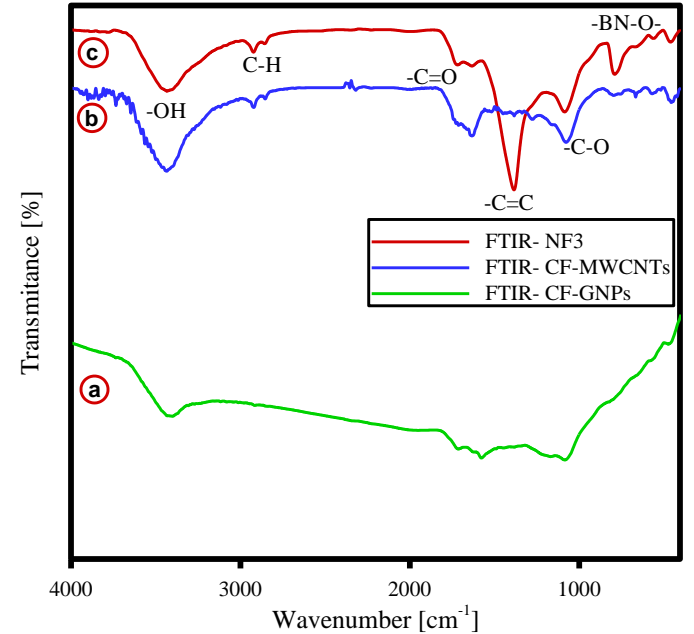

Fig. 6. FTIR spectra of CF-GNPs (a), CF-MWCNTs (b) and Hybrid NF3 (c).

\subsubsection{UV-Vis Spectroscopy}

The UV-vis spectrum of the hybrid water-based nanofluids is displayed in Fig. (-7): It is typical to employ UV-vis spectroscopy to assess if both sedimentation and coolant are stable with time, as predicted from the change of suspension absorbance with time. Beer-Lambert's law stipulates that solution absorbance is proportional directly to absorbing species concentration, for instance, particles found in the solution. The sharp peak noted at $280 \mathrm{~nm}$ for hybrid water-based nanofluid reflected the existence of hybrid and h-BN nanoparticles, respectively. The hybrid nanofluid had no agglomeration or sedimentation, while MWCNTs and GNPs were unstable due to the strong Van der Waals forces that led to agglomeration in most solvents [48].

Another evaluation, known as zeta potential, was applied to assess sample stability [52]. Zeta potential can be related in a direct manner with the dispersed nanofluid stability [53-54]. The rising 
repulsion between particles with similar charges determined dispersion stability. Particles with high-surface charge can lead to the low occurrence of agglomeration [55]. Values of zeta potential for the nanofluids ranging between $<-30 \mathrm{mV}$ and $>+30 \mathrm{mV}$ were linked withconsidered physically-stable colloids [56]. Figure $(8$ and 9 - illustrates the values of zeta potential and particle size distribution, for different hybrid nanofluid samples after one and twenty days. Tables (4 and 5) tabulate-presented the retrieved outcomes. After 20 days, hybrid nanofluid with $0.1 \mathrm{wt} \%$ had high value $(-29.4 \mathrm{mV})$ and slightly minimised-lower value of zeta potential $(-27.3 \mathrm{mV})$. The pristine MWCNTs portrayed shallow values of zeta potential at different concentrations for one and twenty days, respectively. Hence, it is clear that hybrid nanofluid with $0.1 \mathrm{wt} \%$ gave exceptional stability outcomes, in comparison to another hybrid nanofluid.

The average particle size for hybrid nanofluid with $0.05 \mathrm{wt} \%$ was more prominent than that hybrid nanofluid with $0.1 \mathrm{wt} \%$, while the dispersion of particle size for hybrid nanofluid with $0.05 \mathrm{wt} \%$ was $236.1 \mathrm{~nm}$ and $456.3 \mathrm{~nm}$ after one and twenty days, respectively. The results were higher than the other hybrid nanofluid values, whereby a dispersion of particle size for hybrid nanofluid with $0.1 \mathrm{wt} \%$ had been $225.6 \mathrm{~nm}$ and $300.4 \mathrm{~nm}$ after one and twenty days, respectively. The stability of nanofluids via dispersal of hybrid nanofluid with $0.1 \mathrm{wt} \%$ generated high stability suspension, in comparison to another hybrid nanofluid in isolation [49-50].

Table 4. Zeta potential of different hybrid nanofluid after (1-20 days) of preparation.

\begin{tabular}{l|lll}
\hline \multicolumn{3}{c}{ Zeta potential (mV) } \\
\hline Days & NF1 & NF2 & NF3 \\
\hline $\mathbf{1}$ & -25.7 & -26.1 & -29.4 \\
$\mathbf{2 0}$ & -23.5 & -24.6 & -27.3 \\
\hline
\end{tabular}

Commented [SR1]: Be consistent through out the whole manuscript and follow the format of the journal as mentioned by the reviewer as well. Same for table. Some time Fig, sometime Figure, sometimes inside bracket and sometimes no bracket... 
Table 5. The average particle size of different hybrid nanofluid after (1-20 days) of preparation.

\begin{tabular}{l|lll}
\hline \multicolumn{4}{c}{ Particle size (nm) } \\
\hline Days & NF1 & NF2 & NF3 \\
\hline $\mathbf{1}$ & 236.1 & 233.7 & 225.6 \\
$\mathbf{2 0}$ & 456.3 & 387.9 & 300.4 \\
\hline
\end{tabular}

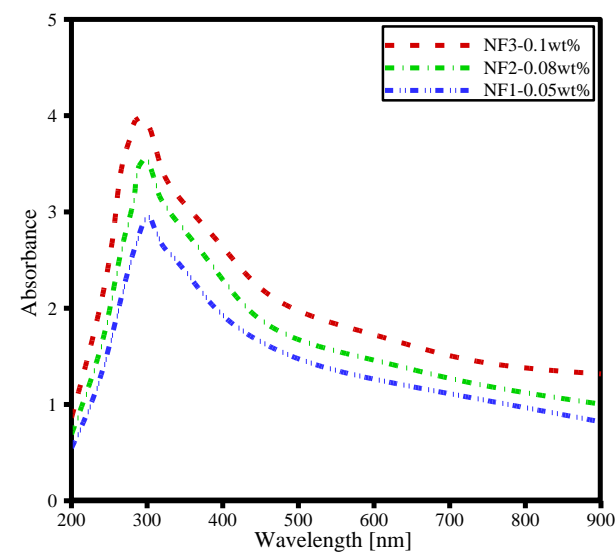

Fig. 7. UV-vis spectrum of different hybrid nanofluid based water nanofluid. 

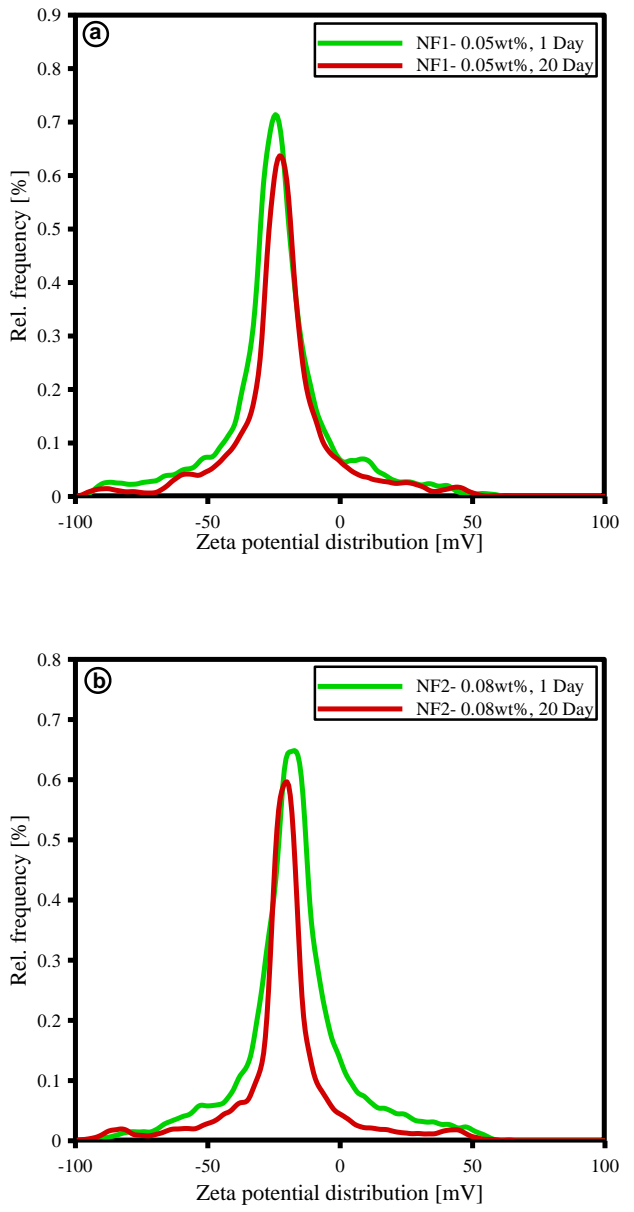


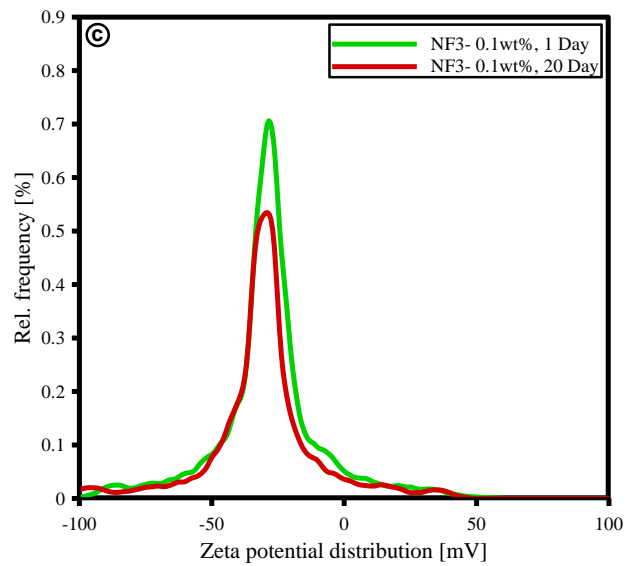

Fig. 8. Zeta potential distribution for 1-20Days: (a) Hybrid NF1(0.05wt\%), (b) Hybrid NF2(0.08wt \%), and (c) Hybrid NF3(0.1wt\%).

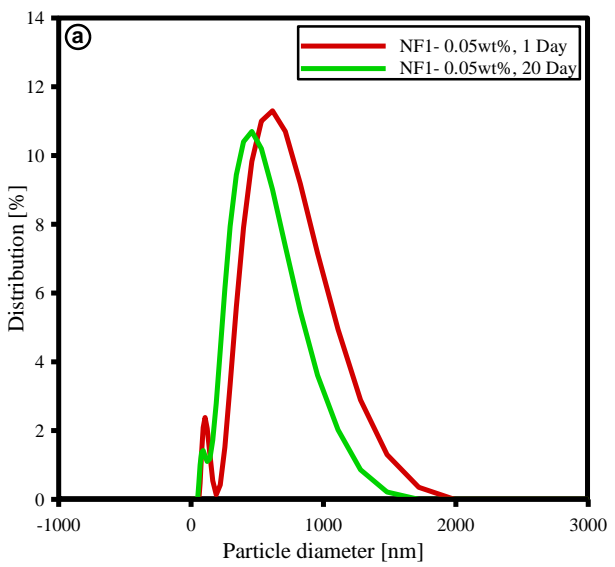



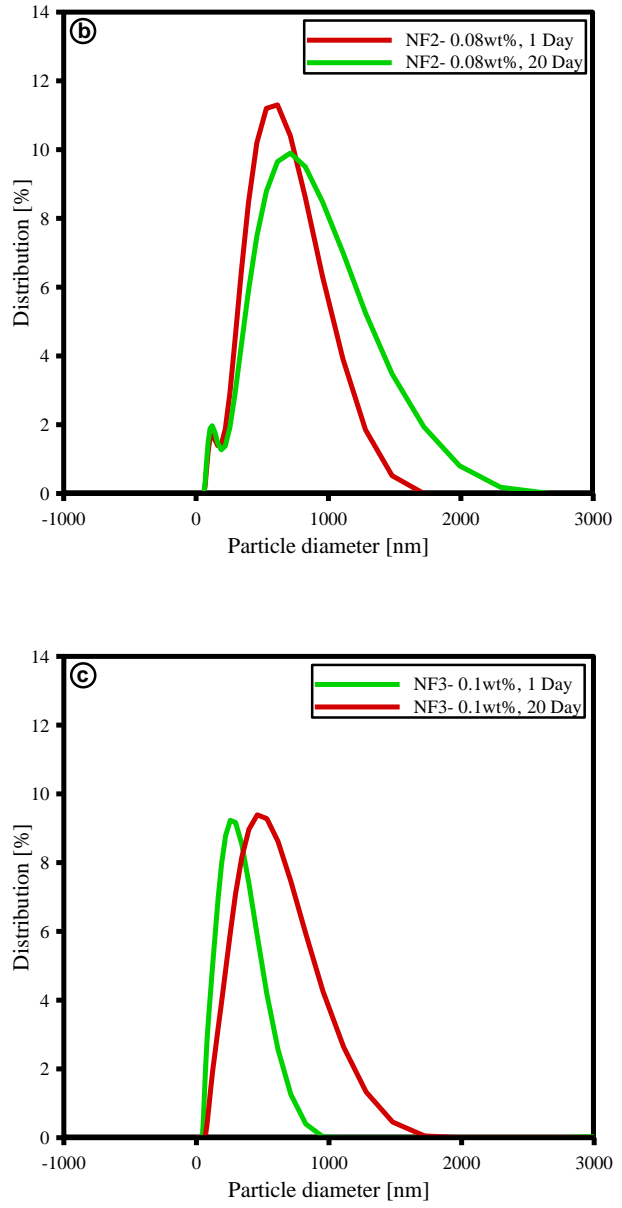

Fig. 9. Particle size distributions for 1-20 Days on (a) Hybrid NF1 (0.05wt\%), (b) Hybrid NF2(0.08wt \%), and (c) Hybrid NF3(0.1wt\%).

\subsection{Thermophysical properties of nanofluids}

\subsubsection{Thermal conductivity}

Fig. (10) illustrates its thermal conductivity (k) based on weight concentration and temperature in DW water. To validate the reliability of the thermal conductivity measurements for distilled water, 
$\mathrm{KD} 2$ Pro was used in the temperature range of $20^{\circ} \mathrm{C}-60^{\circ} \mathrm{C}$. The obtained data are in good agreement with the National Institute of Standards and Technology (NIST) [51] as seen in Fig. 10(a). The average error in the thermal conductivity was found to be $\pm 1.172 \%$. The thermal conductivity of nanofluids enhanced with increment in nanoparticle weight concentration. Fig. 10 shows the reliance of CF-MWCNTs, CF-GNPs hybrid nanocomposite on both weight concentration and temperature in DW. The aspect of $\mathrm{T}$ thermal conductivity improved by $64 \%$ and $12 \%$ at 60 and $20{ }^{\circ} \mathrm{C}$, respectively, for $0.1 \mathrm{wt} \%$ of aqueous CF-MWCNTs, CF-GNPs nanofluids. Better improvement in thermal conductivity was noted for CF-MWCNTs, CF-GNPs with h-BN nanofluid, in comparison to CF-GNPs and CF-MWCNTs nanofluids. The drop in interfacial thermal resistance at a high temperature between solid nanoparticles and base fluid could have enhanced the thermal conductivity of nanofluids [52]. Since heat conduction within solid enhances thermal conductivity, high additives of thermal conductivity are sought for better thermal efficiency [51]. The enhanced thermal conductivity noted in the hybrid nanofluids is attributable to its high inherent thermal conductivity aspect. Superior improvement of thermal conductivity noted for CF-MWCNTs, CF-GNPs with h-BN composite nanofluid is ascribed to the thermal conductivity synergistic impact displayed by both 1D CF-MWCNTs and 2D CF-GNPs. In the literature, the percolation model describes the anomalously significant improvement in thermal conductivity for CF-MWCNTs [53]. The model depicts that the long chains of interconnected networks generated by CF-MWCNTs, CF-GNPs serve as the conducting paths. Building such a system with h-BN requires nanotubes geometry with a high aspect ratio as the exemplary. Since increment in percolation path enhances thermal conductivity, longer percolation path generated by CF-MWCNTs, CF-GNPs with a high aspect ratio improved thermal conductivity to at a greater extent. Similarly, the mixture that comprises of high-aspect-ratio CF-MWCNTs and CF-GNPs, along with h-BN networks, may function as exceptional conducting paths for conduction of heat to improve thermal conductivity. This explains the outstanding performance displayed by the hybrid nanofluids. 

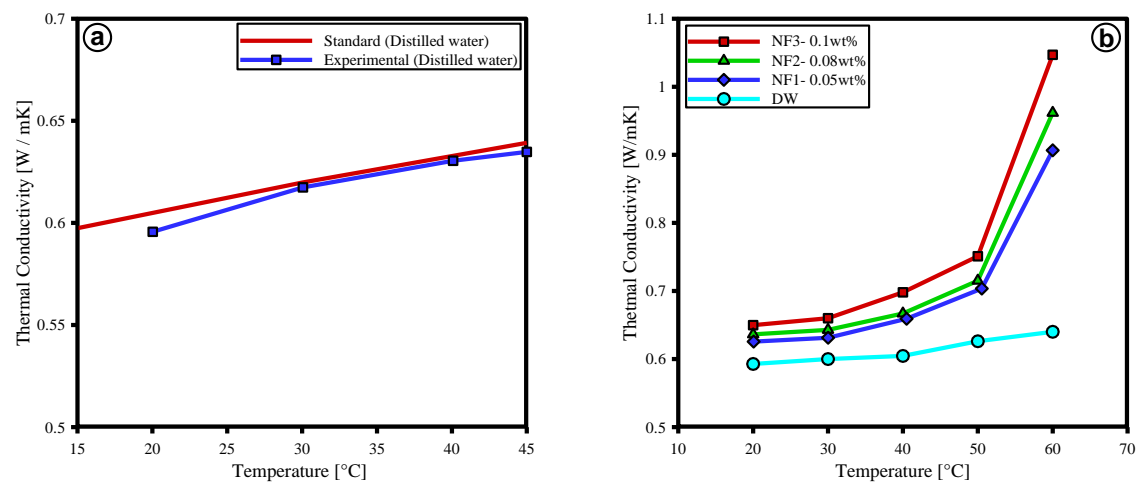

Fig. 10. (a) Comparison of thermal conductivity values of distilled water between NIST standard [49] and KD2 Pro thermal property analyzer measurements, (b) Effect of temperature on the thermal conductivity of hybrid nanofluid.

\subsubsection{Viscosity}

The viscosity measurements obtained using the rotational rheometer have shown good agreement (the average error was $\pm 3.25 \%$ ) with NIST standards as seen in Fig. 11(a) [49]. The viscosity of DW (base fluid) and CF-hybrid nanofluids between 20 and $60^{\circ} \mathrm{C}$ for varying weight concentrations at 200/s shear rate is illustrated in Fig. 11(b). The DW viscosity, which resulted in 0.0011 (Pa s) at $20^{\circ} \mathrm{C}$, is in line with other studies. Increased weight concentration led to increment in viscosity for nanofluid due to the direct impact of weight concentration on the internal shear stress of fluid [54]. Increased temperature decreased viscosity due to weak adhesion between inter-particle and inter-molecular [53]. Viscosity enhanced by $33 \%$ at $0.1 \%$ nanofluid weight concentration in comparison to DW viscosity at $60{ }^{\circ} \mathrm{C}$.

Figs. 11(b-c) display the variation of viscosity with shear rate for three hybrids of MWCNTs and GNPs with h-BN at 0.05 wt. $\%, 0.08 w t . \%$, and $0.1 \mathrm{wt} . \%$, respectively. Both hybrids nanofluids 
indicated non-Newtonian behaviour, as the viscosity of both nanofluids varied non-linearly by shear rate. On the contrary, the h-BN decorated (CF-MWCNTs+CF-GNPs) water nanofluids exhibited dilatant behaviour, as the viscosity of all the nanofluid samples increased relative to increment in shear rate. The viscosity for all decorated hybrid nanofluids decreased as concentration and temperature were increased.
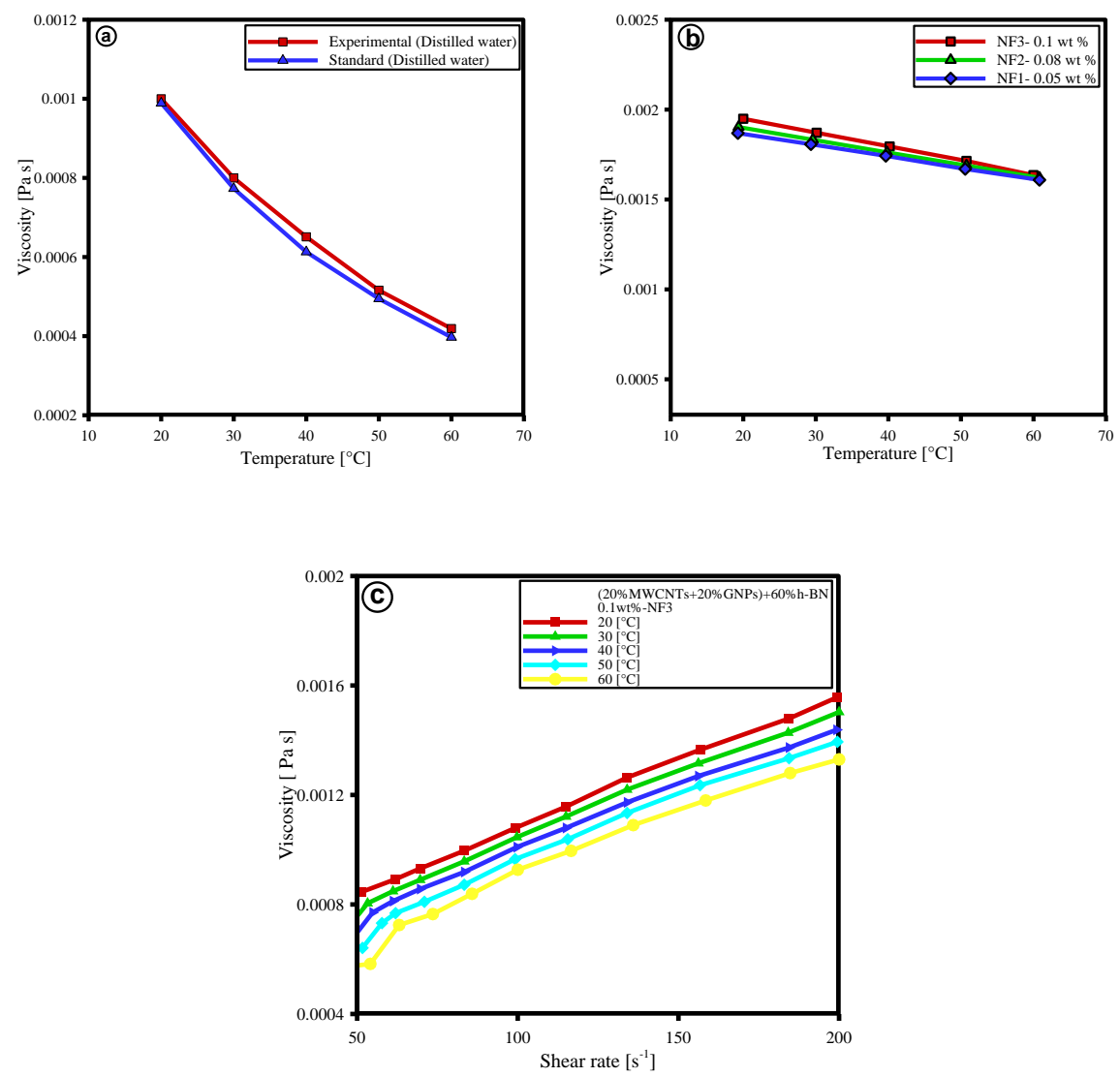
Fig. 11. (a) Distilled water between NIST standard [49] and experiments, (b) Effect of the viscosity on the temperature at different concentrations, (c) Effect of the shear rate on the viscosity at various temperature of hybrid nanofluid.

\subsubsection{Specific heat capacity}

Studies on the impact of nanoparticle concentration on nanofluids specific heat are somewhat limited [53-54]. The specific heat capacity of hybrid nanofluids as a function of temperatures and concentration is portrayed in Fig. (12), wherein nanofluid samples displayed higher specific heat capacity than that obtained for DW. Specific heat capacity is enhanced with increment in a weight concentration of particles. For instance, an increase of $4 \%$ and $11 \%$ of nanofluids specific heat were obtained at $60^{\circ} \mathrm{C}$ at 0.05 and $0.10 \mathrm{wt} . \%$ nanoparticles, respectively. Prior studies reported that the addition of nanoparticles increased specific heat capacity, despite some contradicting outcomes [57]. Apparently, the aspect of specific heat capacity of both base fluid and nanoparticles increased the heat capacity of nanofluids, apart from changing the solid-liquid interfacial free energy due to altered, suspended nanoparticles. Greater nanoparticle surface area generates the superior impact of surface free energy on the heat capacity of nanocomposite materials [54].

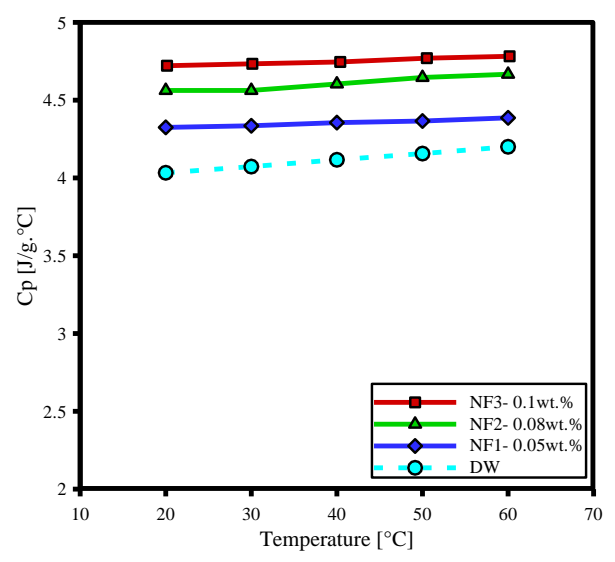

Fig. 12. Specific heat versus temperature of hybrid nanofluid at varying concentration. 


\subsection{Water as Working Fluid}

In the case of water as working fluid, this study measured the variation of ambient air temperature $\left(T_{a}\right)$, fluid temperatures at the collector inlet $\left(T_{i}\right)$ and outlet $\left(T_{o}\right)$, as well as solar irradiation $\left(G_{t}\right)$. Fig. (13) presentstabulates the average $G_{t}$ and $T_{a}$, as well as $T_{i}$ and $T_{o}$ for empirical testing during clear sky. While neglecting the transient effect, the thermal performance of the system had been predicted under the steady-state setting. Fig. (13) shows the outcomes for a sample day on an hourly basis. As predicted, an increment of solar radiation was noted until solar noon ( 13 hours) and decreased after that. Increment in ambient air temperature and absorption of radiation heat by water in the riser tubes increased the temperature. The temperature of the fluid outlet fell when both solar irradiation and ambient air temperature decreased.

The useful thermal power $\left(\mathrm{Q}_{\mathrm{u}}\right)$ absorbed by the collector is shown in Fig. (14) in comparison with the temperature difference between ambient air and collector inlet as a driving force. The thermal power followed the same trend of solar radiation because it is affected mostly by the incoming irradiation on the collector.

Tests that involved FPSC and DW (absorber fluid) had been carried out between MAYMay and SEPTEMBER-September 2019 from 8 a.m. to 5 p.m. on sunny days with an average $2 \mathrm{~m} / \mathrm{s}$ wind speed. and solar radiation recorded using Thermo Anemometer and Tenmars Solar Power Meter, respectively. With $1 \%$ accuracy, the flow rate was determined using Bronkhorst, an electromagnetic flow meter. Tests were conducted on the solar collector at 2,3 , and $4 \mathrm{~L} / \mathrm{min}$ flow rate-range. The quasi-steady empirical outputs are tabulated-presented based on collector efficiency against lowered temperature factor, $\left(\mathrm{T}_{\mathrm{i}}-\mathrm{T}_{\mathrm{a}}\right) / \mathrm{G}_{\mathrm{t}}$ with 15 minutes of interval time. Based on the selected operating setting to ascertain repeatability; this study only considered consistent empirical data. Several aspects, namely cloudy sky and sudden weather change, affected the reproducibility of the empirical data. The varying efficiency of the collector based on the DW (base fluid) flow rate as the absorber fluid is presented in Fig. (15). The increased flow rate of fluid increased the FPSC efficiency. The curve fit line slope based on the data reflects the discarded energy parameter, $\mathrm{F}_{\mathrm{R}} \mathrm{U}_{\mathrm{L}}$. With 2 and $4 \mathrm{~L} / \mathrm{min}$ base fluid flow rates, the $\mathrm{F}_{\mathrm{R}} \mathrm{U}_{\mathrm{L}}$ values were 6.3265 and 7.9585 , respectively. Meanwhile, for $2 \mathrm{~L} / \mathrm{min}$ DW flow rate, the intercept of the curve fit line for data plotted against flow rate or better known as the absorbed energy parameter $F_{R}(\tau \alpha)$, the result was 0.6876 , while 0.7715 for $4 \mathrm{~L} / \mathrm{min}$, the highest flow rate. Table $(6)$ abulates-presents the values of $\mathrm{F}_{\mathrm{R}} \mathrm{U}_{\mathrm{L}}, \mathrm{F}_{\mathrm{R}}(\tau \alpha)$, and regression coefficient $\left(\mathrm{R}^{2}\right)$ of curve fit lines retrieved from the empirical tests. 
Improvement in $\mathrm{F}_{\mathrm{R}}(\tau \alpha)$ for base fluid with $4 \mathrm{~L} / \mathrm{min}$ flow rate was $12.2 \%$, while the value of $\mathrm{F}_{\mathrm{R}} \mathrm{U}_{\mathrm{L}}$ was $25.8 \%$ when compared to the results obtained for $2 \mathrm{~L} / \mathrm{min}$ flow rate [58]. The increment was noted for $\mathrm{F}_{\mathrm{R}}(\tau \alpha)$ values upon increased flow rate, whereas $\mathrm{F}_{\mathrm{R}} \mathrm{U}_{\mathrm{L}}$ remained constant. Hence, the efficiency of FPSC may be enhanced with an increased absorber fluid volume flow rate.

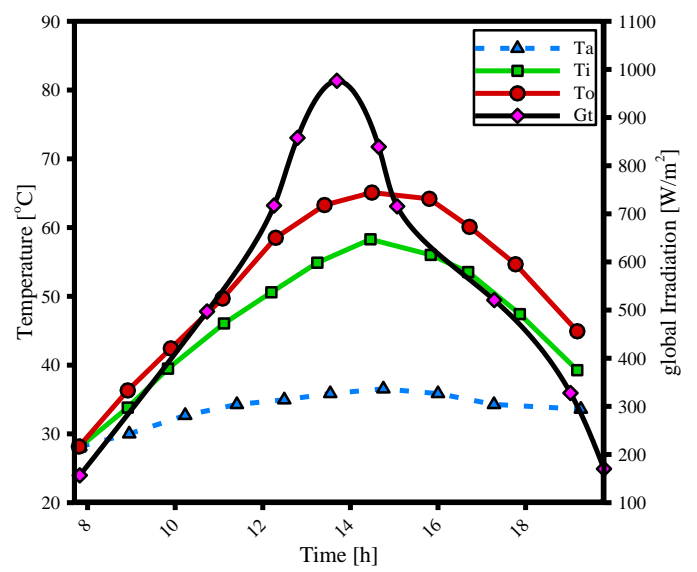

Fig. 13. Collector temperatures and radiation graphics for water.

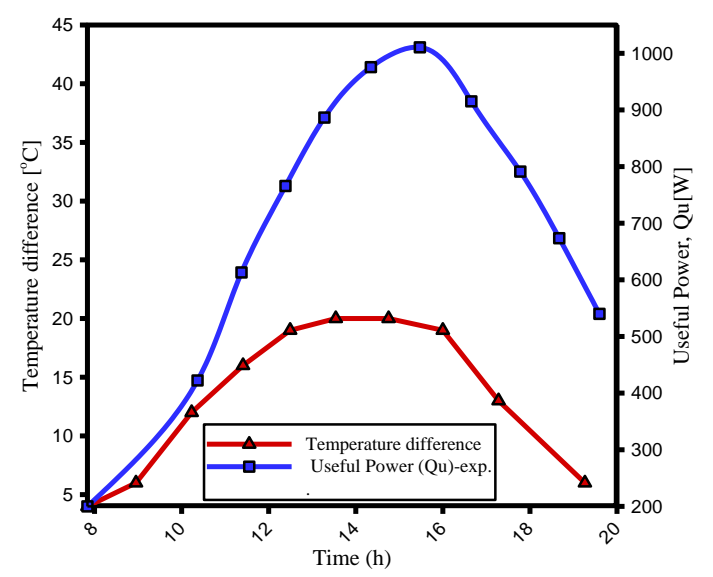

Fig. 14. Useful thermal power variations versus the temperature difference. 


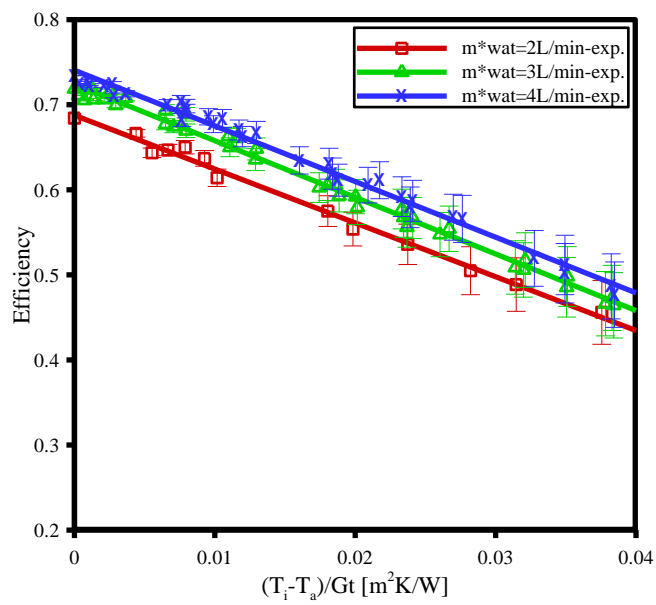

Fig. 15. Variation of the collector efficiency with the flow rate of base fluid.

Table 6. Values of $F_{R} U_{L}, F_{R}(\tau \alpha)$ and $R^{2}$ for the base fluid at various flow rates.

\begin{tabular}{llll}
\hline Working fluid flow rate(L/min) & $\mathbf{F}_{\mathbf{R}} \mathbf{U}_{\mathbf{L}}$ & $\mathbf{F}_{\mathbf{R}}(\boldsymbol{\tau} \boldsymbol{\alpha})$ & $\mathbf{R}^{\mathbf{2}}$ \\
\hline Water at 2 L/minlpm (exp) & 6.3265 & 0.6876 & 0.9816 \\
Water at $3 \underline{\mathrm{L} / \mathrm{min}} \mathrm{lpm}$ (exp) & 6.6567 & 0.7187 & 0.993 \\
Water at $4 \underline{\mathrm{L} / \mathrm{min}} 1 \mathrm{pm}$ (exp) & 6.5424 & 0.7405 & 0.9965 \\
\hline
\end{tabular}

\subsection{Hybrid Nanofluid as Working Fluid}

The results for the efficiency of FPSC against $\left(\mathrm{T}_{\mathrm{i}}-\mathrm{T}_{\mathrm{a}}\right) / \mathrm{G}_{t}$ for $2-4 \mathrm{~L} / \mathrm{min}$ flow rates of hybrid nanofluid and 0.05-0.10 wt \% are displayed in Figs. 16(a-c). Increment in absorbed energy parameter was recorded with an increased flow rate, thus enhancing the efficiency of FPSC, which was due to reduced thermal boundary layer thickness that increased the rate of heat transfer. With DW as the base fluid, hybrid nanofluids were prepared at $0.05,0.08$, and $0.10 \mathrm{wt} . \%$ using a mass 
balance and the density of the samples was determined prior to analyses. The experimental procedure began with a low concentration $(0.05$ wt. \%), followed by 0.08 and 0.10 wt.\%. Figs. 17(a-c) illustrate the efficiency of FPSC based on the weight concentrations of the hybrid nanofluids and flow rates $(2-4 \mathrm{~L} / \mathrm{min})$ against $\left(\mathrm{T}_{\mathrm{i}}-\mathrm{T}_{\mathrm{a}}\right) / \mathrm{G}_{\mathrm{t}}$. To determine the FPSC characteristic parameters, the empirical data had been fitted with a linear curve. The comparison between values of $\mathrm{F}_{\mathrm{R}} \mathrm{U}_{\mathrm{L}}, \mathrm{F}_{\mathrm{R}}(\tau \alpha)$, and $\mathrm{R}^{2}$ for different flow rates and weight concentrations of hybrid nanofluid is provided in Table (7). Upon comparing the $\mathrm{F}_{\mathrm{R}}(\tau \alpha)$ values for the nanofluid with $2 \mathrm{~L} / \mathrm{min}$ flow rate and $0.05 \mathrm{wt} \%$ weight concentration, results obtained for 0.08 and $0.10 \mathrm{wt} \%$ displayed improvement by $3 \%$ and $10.82 \%$, accordingly. Table $(8)$ displays the improved values of $F_{R} U_{L}$ and $\mathrm{F}_{\mathrm{R}}(\tau \alpha)$ for $0.05 \mathrm{wt} \%$. This trend conforms with the results of earlier studies by Michael and Iniyan [29]. In comparison to base fluid, the values of $\mathrm{F}_{\mathrm{R}}(\tau \alpha)$ were $7.591 \%, 10.719 \%$, and $19.240 \%$ for $2 \mathrm{~L} / \mathrm{min}$ absorber fluid flow rate at $0.05,0.08$, and $0.10 \mathrm{wt} \%$, respectively. Table $(9)$ presents the summary of improvements noted for $\mathrm{F}_{\mathrm{R}}(\tau \alpha)$ and $\mathrm{F}_{\mathrm{R}} \mathrm{U}_{\mathrm{L}}$ of the nanofluids at varied weight concentrations with a given flow rate, in comparison to base fluid flow rate [56].
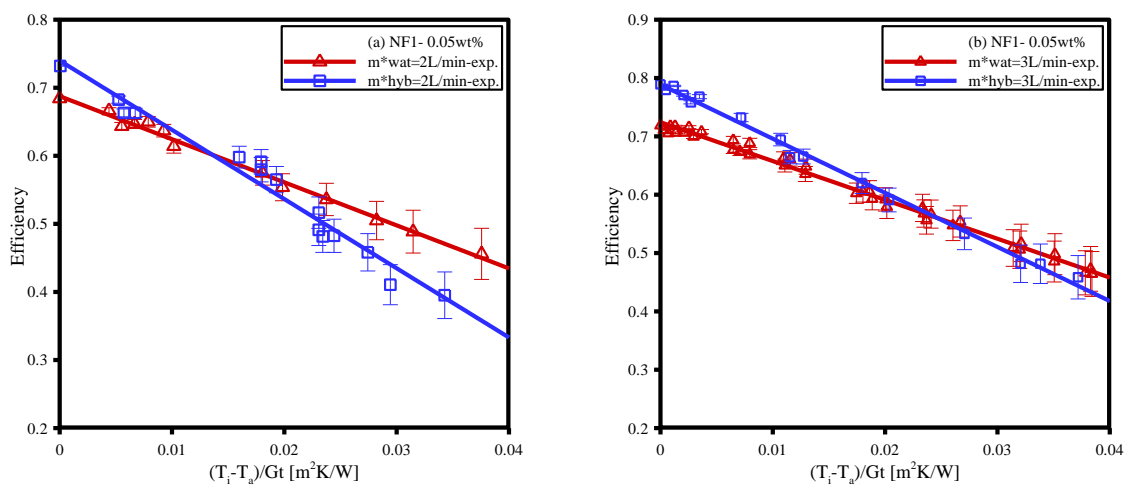


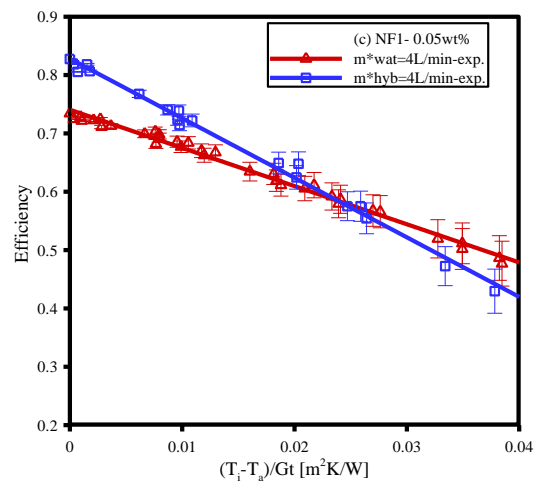

Fig. 16. Comparison of the FPSC efficiency between the base fluid and hybrid nanofluid for different flow rate values.
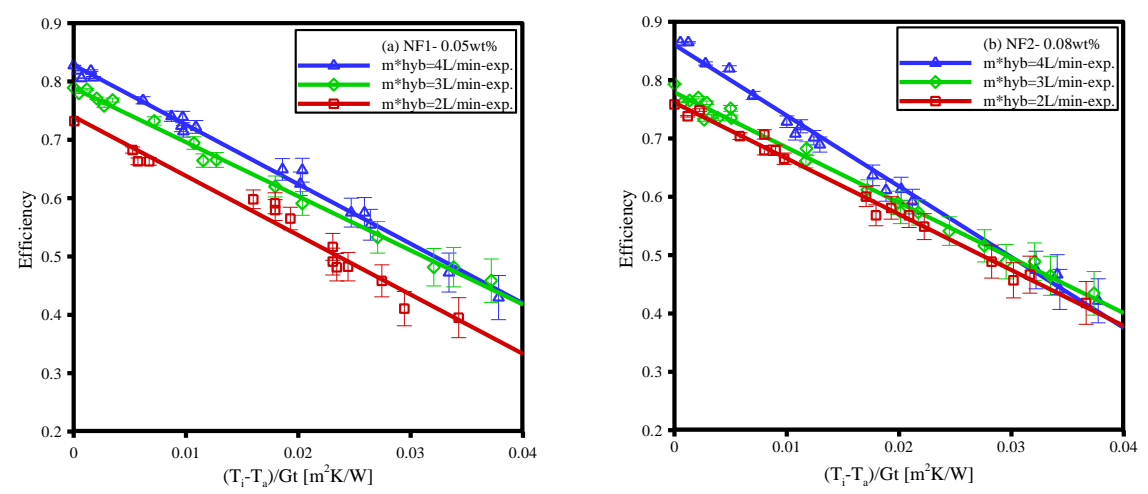


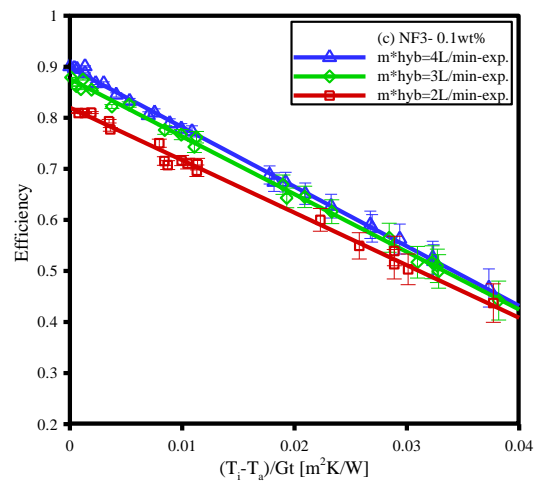

Fig. 17. Effect of the different flow rate of the hybrid nanofluid on the FPSC efficiency.

Table 7. Comparison of the values of $\mathrm{F}_{\mathrm{R}} \mathrm{U}_{\mathrm{L}}, \mathrm{F}_{\mathrm{R}}(\tau \alpha)$ and $\mathrm{R}^{2}$ for hybrid NF with different wt.\% and flow rate values.

\begin{tabular}{|c|c|c|c|c|}
\hline $\begin{array}{c}\text { Hybrid NF } \\
\text { concentration }\end{array}$ & $\begin{array}{c}\text { Flow rate } \\
(\mathbf{L} / \mathbf{m i n})\end{array}$ & $\mathbf{F}_{\mathbf{R}} \mathbf{U}_{\mathbf{L}}$ & $\mathbf{F}_{\mathbf{R}}(\boldsymbol{\tau} \boldsymbol{\alpha})$ & $\mathbf{R}^{\mathbf{2}}$ \\
\hline \multirow{3}{*}{$\mathbf{0 . 0 5}$ wt\% } & 2 & 10.0168 & 0.7398 & 0.9601 \\
\cline { 2 - 5 } & 3 & 9.27556 & 0.7887 & 0.9983 \\
\cline { 2 - 5 } & 4 & 10.0206 & 0.82806 & 0.9993 \\
\hline \multirow{3}{*}{$\mathbf{0 . 0 8}$ wt\% } & 2 & 9.56393 & 0.76131 & 0.9994 \\
\cline { 2 - 5 } & 3 & 9.45571 & 0.7790 & 0.9989 \\
\hline \multirow{3}{*}{$\mathbf{0 . 1}$ wt\% } & 2 & 10.2128 & 0.86045 & 0.9977 \\
\cline { 2 - 5 } & 3 & 10.0291 & 0.8199 & 0.9999 \\
\cline { 2 - 5 } & 4 & 11.296 & 0.8762 & 0.9968 \\
\hline
\end{tabular}

Table 8. Enhancement of the values of $F_{R} U_{L}$ and $F_{R}(\tau \alpha)$ compared to that of $0.05 w t \%$.

\begin{tabular}{|c|c|c|c|}
\hline $\begin{array}{c}\text { Hybrid NF } \\
\text { concentration }\end{array}$ & Flow rate (L/min) & $\mathbf{F}_{\mathbf{R}} \mathbf{U}_{\mathbf{L}}$ & $\mathbf{F}_{\mathbf{R}}(\boldsymbol{\tau} \boldsymbol{\alpha})$ \\
\hline \multirow{3}{*}{$\mathbf{0 . 0 8}$ wt\% } & 2 & -4.5 & 2.9 \\
\cline { 2 - 4 } & 3 & 1.9 & -1.2 \\
\cline { 2 - 4 } & 4 & 1.9 & 3.2 \\
\cline { 2 - 4 } $\mathbf{*} \mathbf{0 . 1}$ wt\% & 2 & 0.1 & 10.8 \\
\cline { 2 - 4 } & 3 & 21.7 & 11 \\
\hline
\end{tabular}


Table 9. Enhancement of $F_{R} U_{L}$ and $F_{R}(\tau \alpha)$ for the nanofluids compared with the base fluid.

\begin{tabular}{|c|c|c|c|}
\hline $\begin{array}{c}\text { Hybrid NF } \\
\text { concentration }\end{array}$ & Flow rate (L/min) & $\mathbf{F}_{\mathbf{R}} \mathbf{U}_{\mathbf{L}}$ & $\mathbf{F}_{\mathbf{R}}(\boldsymbol{\tau} \boldsymbol{\alpha})$ \\
\hline \multirow{3}{*}{$\mathbf{0 . 0 5}$ wt\% } & 2 & 58.3 & 7.5 \\
\cline { 2 - 4 } & 3 & 39.3 & 9.7 \\
\cline { 2 - 4 } & 4 & 53.1 & 11.8 \\
\hline \multirow{3}{*}{0.08 wt\% } & 2 & 51.1 & 10.7 \\
\cline { 2 - 4 } & 3 & 42 & 8.3 \\
\hline \multirow{3}{*}{$\mathbf{0 . 1}$ wt\% } & 2 & 56.1 & 16.1 \\
\cline { 2 - 4 } & 3 & 58.5 & 21 \\
\hline
\end{tabular}

\section{Conclusions}

This present study evaluated the impacts of CF-MWCNTs and CF-GNPs hybrid with h$\mathrm{BN}$ in DW on the improvement in the performance displayed by FPSC. Characterization was performed to determine the thermophysical properties revealed the positive responses of the hybrid fluids to increased particle weight concentration and temperature. As a result, thermal conductivity had found to be increased by $12 \%$ and $64 \%$ at 20 and $60^{\circ} \mathrm{C}$, respectively, at $0.10 \mathrm{wt} . \%$. As for rheological and thermophysical-properties, the h-BN was less viscous than CF-MWCNTs and CFGNPs. The h-BN fluid adhered to the non-linear trend between shear stress and strain resultsgraph. Both CF-MWCNTs and CF-GNPs were highly viscous and possessed more specific heat. As the hybrid nanofluid was positively associated with rheological properties, its combination with high conductivity of CF-MWCNTs and CF-GNPs is the same as the hybrid combination of h-BN. The performance of FPSC using hybrid nanofluid appeared to be better than the use of nanofluid in isolation. The thermal efficiency of the system improved-found up to $85 \%$ for $0.10 \mathrm{wt} \%$ of hybrid nanofluid, which was $20 \%$ higher than $\mathrm{DW}$ at $4 \mathrm{~L} / \mathrm{min}$ flow rate. Improvement of $\mathrm{F}_{\mathrm{R}}(\tau \alpha)$ and $\mathrm{F}_{\mathrm{R}} \mathrm{U}_{\mathrm{L}}$ for base fluid at $4 \mathrm{~L} / \mathrm{min}$ flow rate was $8 \%$ and $4 \%$, in comparison to those recorded at $2 \mathrm{~L} / \mathrm{min}$; 
The maximum increment for $\mathrm{F}_{\mathrm{R}}(\tau \alpha)$ and $\mathrm{F}_{\mathrm{R}} \mathrm{U}_{\mathrm{L}}$ were $21.9 \%$ and $78.3 \%$, respectively at $4 \mathrm{~L} / \mathrm{min}$ flow rate and 0.10 wt.\% for the hybrid nanofluid. Based on the comparative analysis, the performance of FPSC with hybrid nanofluid seemed to be significantly better than using the nanofluid in isolation. Conclusively, the overall performance FPSC of the hybrid 0.10 wt.\% was better than that of $0.05 \& 0.08$ wt.\% hybrid nanofluids.

Conflicts of Interest: The authors declare no conflict of interest.

\section{Acknowledgements}

The authors of current work wish to thank University Teknologi PETRONAS and SUNWAY

University, "R. Saidur would like to acknowledge the financial support provided by the Sunway

University through the project no\# STR-RCTR-RCNMET-001-2019" for their facilities and support to conduct this research work.

\begin{tabular}{|c|c|c|c|}
\hline \multicolumn{4}{|l|}{ Nomenclatue } \\
\hline DLS & Dynamic Light Scattering & Tw-80 & Tween-80 \\
\hline ELS & Electrophoretic Light Scattering & Tx-100 & TritonX-100 \\
\hline ASHRAE & $\begin{array}{l}\text { American Society of heating, refrigerating } \\
\text { and air-conditioning engineers }\end{array}$ & $\mathrm{Fe}_{3} \mathrm{O}_{4}$ & Iron (II, III) oxide (ferrous ferric oxide) \\
\hline $\exp$ & Experimental & $\mathrm{TiO}_{2}$ & Titanium dioxide (titania) \\
\hline GNPs & Graphene nanoplatelets & SDBS & Sodium dodecyl benzene sulfonate \\
\hline MWCNTs & Multi-Walled Carbon Nanotubes & GA & Gum Arabic \\
\hline SDS & Sodium dodecyl sulfate & CTAB & Cetyltrimethylammonium bromide \\
\hline SSA & Specific surface area $\left(\mathrm{m}^{2} / \mathrm{g}\right)$ & CF-GNPs & Covalent Functionalization GNPs \\
\hline Gt & Global radiation $\left(\mathrm{W} / \mathrm{m}^{2}\right)$ & CF-MWCNTs & Covalent Functionalization MWCNTs \\
\hline h-BN & Hexagonal boron nitride & $\mathrm{m}^{*}$ & Mass flow rate $(\mathrm{L} / \mathrm{m})$ \\
\hline FPSCs & Flat Plate Solar Collectors & $\mathrm{Cp}$ & Specific heat $(\mathrm{J} / \mathrm{kgK})$ \\
\hline UV-vis & Ultraviolet-visible spectrophotometry & CNTs & Carbon nanotubes \\
\hline DSC & Differential scanning calorimeter & DW & Distilled water \\
\hline FESEM & $\begin{array}{l}\text { Field emission scanning electron } \\
\text { microscopy }\end{array}$ & EG & Ethylene glycol \\
\hline FTIR & Fourier transform infrared spectroscopy & TGA & Thermo-gravimetric analysis \\
\hline P-MWCNTs & Pristine MWCNTs & EDX & Energy Dispersive Spectroscopy \\
\hline P-GNPs & Pristine GNPs & $\mathrm{R}^{2}$ & regression coefficient \\
\hline $\mathrm{T}_{\mathrm{a}}$ & ambient temperature $\left({ }^{\circ} \mathrm{C}\right)$ & $\eta_{i}$ & efficiency of flat-plate solar collector \\
\hline
\end{tabular}




\begin{tabular}{|c|c|c|c|}
\hline $\mathrm{T}_{\mathrm{i}}$ & inlet fluid temperature of collector $\left({ }^{\circ} \mathrm{C}\right)$ & wt & weight concentration \\
\hline FETEM & $\begin{array}{l}\text { Field emission transmission electron } \\
\text { microscopy }\end{array}$ & XRD & $\mathrm{X}$-ray diffraction \\
\hline $\operatorname{Re}$ & Reynolds number & $\mathrm{U}_{\mathrm{L}}$ & Heat loss coefficient $\left(\mathrm{W} / \mathrm{m}^{2} \mathrm{~K}\right)$ \\
\hline NF & Nanofluid(1,2,3) & $F_{R}$ & Heat removal factor \\
\hline
\end{tabular}

\section{References}

[1] M. S. Mohammad Mehrali1*, Sara Tahan Latibari1, Marc A. Rosenz, Amir Reza Akhiani1, H. S. C. M. 1* Naghavi1, Emad Sadeghinezhad4, and E. Nejad3, Majeed Mohammadi_MMehrali4, "From rice husk to high performance shape stabilized phase change materials for thermal energy storage,” RSC Adv., vol. 6, no. 51, pp. 45595-45604, 2016.

[2] D. Aydin, Z. Utlu, and O. Kincay, "Thermal performance analysis of a solar energy sourced latent heat storage," Renew. Sustain. Energy Rev., vol. 50, pp. 1213-1225, 2015.

[3] E. Halawa, K. C. Chang, and M. Yoshinaga, "Thermal performance evaluation of solar water heating systems in Australia, Taiwan and Japan e A comparative review," Renew. Energy, 2015.

[4] I. Visa et al., "Design and experimental optimisation of a novel flat plate solar thermal collector with trapezoidal shape for facades integration," Appl. Therm. Eng., vol. 90, pp. 432-443, Nov. 2015.

[5] X. Wang, Y. He, X. Liu, L. Shi, and J. Zhu, "Investigation of photothermal heating enabled by plasmonic nanofluids for direct solar steam generation," Sol. Energy, vol. 157, pp. $35-46,2017$.

[6] M. Esen, "Thermal performance of a solar cooker integrated vacuum-tube collector with heat pipes containing different refrigerants," Sol. Energy, vol. 76, no. 6, pp. 751-757, 2004. 
[7] M. Esen and H. Esen, "Experimental investigation of a two-phase closed thermosyphon solar water heater," Sol. Energy, vol. 79, no. 5, pp. 459-468, 2005.

[8] H. Alipour, A. Karimipour, M. R. Safaei, D. T. Semiromi, and O. A. Akbari, "Influence of T-semi attached rib on turbulent flow and heat transfer parameters of a silver-water nanofluid with different volume fractions in a three-dimensional trapezoidal microchannel," Phys. E Low-dimensional Syst. Nanostructures, vol. 88, pp. 60-76, Apr. 2017.

[9] H. Kim, J. Kim, and H. Cho, "Experimental study on performance improvement of U-tube solar collector depending on nanoparticle size and concentration of Al2O3 nanofluid," Energy, vol. 118, pp. 1304-1312, Jan. 2017.

[10] S. Suresh, K. P. Venkitaraj, P. Selvakumar, and M. Chandrasekar, "Synthesis of Al2O3$\mathrm{Cu}$ /water hybrid nanofluids using two step method and its thermo physical properties," Colloids Surfaces A Physicochem. Eng. Asp., vol. 388, no. 1-3, pp. 41-48, Sep. 2011.

[11] L. S. Sundar, M. K. Singh, and A. C. M. Sousa, "Enhanced heat transfer and friction factor of MWCNT-Fe3O4/water hybrid nanofluids," Int. Commun. Heat Mass Transf., vol. 52, pp. 73-83, Mar. 2014.

[12] T. T. Baby and R. Sundara, "Synthesis and transport properties of metal oxide decorated graphene dispersed nanofluids," J. Phys. Chem. C, vol. 115, no. 17, pp. 8527-8533, 2011.

[13] A. Amiri, M. Shanbedi, H. Eshghi, S. Z. Heris, and M. Baniadam, "Highly Dispersed Multiwalled Carbon Nanotubes Decorated with Ag Nanoparticles in Water and Experimental Investigation of the Thermophysical Properties,” 2012.

[14] M. A. Safi, A. Ghozatloo, and A. A. Hamidi, "Calculation of Heat Transfer Coefficient of MWCNT-TiO 2 Nanofluid in Plate Heat Exchanger,” Int. J. Nanosci., vol. 10, no. 3, pp. 
153-162, 2014.

[15] D. Huang, Z. Wu, and B. Sunden, "Effects of hybrid nanofluid mixture in plate heat exchangers," Exp. Therm. FLUID Sci., vol. 72, pp. 190-196, 2016.

[16] H. Yarmand et al., "Graphene nanoplatelets - silver hybrid nanofluids for enhanced heat transfer," Energy Convers. Manag., vol. 100, pp. 419-428, 2015.

[17] O. A. Hussein, K. Habib, R. Saidur, A. S. Muhsan, S. Shahabuddin, and O. A. Alawi, "The influence of covalent and non-covalent functionalization of GNP based nanofluids on its thermophysical, rheological and suspension stability properties," RSC Adv., vol. 9, no. 66, pp. 38576-38589, 2019.

[18] H. Yarmand et al., "Study of synthesis, stability and thermo-physical properties of graphene nanoplatelet / platinum hybrid nano fl uid th," Int. Commun. Heat Mass Transf., vol. 77, pp. 15-21, 2016.

[19] S. Sarbolookzadeh Harandi, A. Karimipour, M. Afrand, M. Akbari, and A. D’Orazio, “An experimental study on thermal conductivity of F-MWCNTs-Fe3O4/EG hybrid nanofluid: Effects of temperature and concentration," Int. Commun. Heat Mass Transf., vol. 76, pp. 171-177, Aug. 2016.

[20] T. Ikuno, T. Sainsbury, D. Okawa, J. M. J. Fréchet, and A. Zettl, “Amine-functionalized boron nitride nanotubes," Solid State Commun., vol. 142, no. 11, pp. 643-646, Jun. 2007.

[21] T. Sainsbury, T. Ikuno, D. Okawa, D. Pacilé, J. M. J. Fréchet, and A. Zettl, "Selfassembly of gold nanoparticles at the surface of amine- and thiol-functionalized boron nitride nanotubes,” J. Phys. Chem. C, vol. 111, no. 35, pp. 12992-12999, 2007.

[22] E. Sadeghinezhad et al., "An experimental and numerical investigation of heat transfer enhancement for graphene nanoplatelets nanofluids in turbulent flow conditions," Int. J. 
Heat Mass Transf., vol. 81, pp. 41-51, 2015.

[23] A. A. Hussien, M. Z. Abdullah, N. Yusop, M. A. Al-nimr, and M. A. Atieh, "International Journal of Heat and Mass Transfer Experiment on forced convective heat transfer enhancement using MWCNTs / GNPs hybrid nanofluid and mini-tube,” Int. J. Heat Mass Transf., vol. 115, pp. 1121-1131, 2017.

[24] E. Natarajan and R. Sathish, "Role of nanofluids in solar water heater," Int. J. Adv. Manuf. Technol., pp. 3-7, 2009.

[25] T. Yousefi, F. Veysi, E. Shojaeizadeh, and S. Zinadini, “33,” Renew. Energy, vol. 39, no. 1, pp. 293-298, Mar. 2012.

[26] S. Vijayakumar, S. Nagamuthu, and G. Muralidharan, "Supercapacitor studies on NiO nanoflakes synthesized through a microwave route," ACS Appl. Mater. Interfaces, vol. 5, no. 6, pp. 2188-2196, 2013.

[27] Z. Said, M. H. Sajid, R. Saidur, G. A. Mahdiraji, and N. A. Rahim, "Evaluating the Optical Properties of TiO2 Nanofluid for a Direct Absorption Solar Collector,” Numer. Heat Transf. Part A Appl., vol. 67, no. 9, pp. 1010-1027, 2015.

[28] Z. Said, R. Saidur, M. A. Sabiha, N. A. Rahim, and M. R. Anisur, "ScienceDirect Thermophysical properties of Single Wall Carbon Nanotubes and its effect on exergy efficiency of a flat plate solar collector," vol. 115, pp. 757-769, 2015.

[29] J. J. Michael and S. Iniyan, "Performance of copper oxide/water nanofluid in a flat plate solar water heater under natural and forced circulations," Energy Convers. Manag., vol. 95, pp. 160-169, 2015.

[30] A. Ahmadi, D. Domiri, and F. Jafarkazemi, “Analysis of utilizing Graphene nanoplatelets to enhance thermal performance of flat plate solar collectors," vol. 126, pp. 1-11, 2016. 
[31] S. K. Verma, A. K. Tiwari, and D. S. Chauhan, "Performance augmentation in flat plate solar collector using MgO/water nanofluid,” Energy Convers. Manag., vol. 124, pp. 607$617,2016$.

[32] M. Verma, S. S. Chauhan, S. K. Dhawan, and V. Choudhary, "Graphene nanoplatelets/carbon nanotubes/polyurethane composites as efficient shield against electromagnetic polluting radiations," Compos. Part B Eng., vol. 120, pp. 118-127, 2017.

[33] Moore et al., "Physicochemical characterization of a novel graphene-based magnetic resonance imaging contrast agent," Int. J. Nanomedicine, p. 2821, 2013.

[34] N. M. Fadhillahanafi, K. Y. Leong, and M. S. Risby, "Stability and thermal conductivity characteristics of carbon nanotube based nanofluids," Int. J. Automot. Mech. Eng., vol. 8, no. 1 , pp. 1376-1384, 2013.

[35] S. Kalogirou, “Solar Energy Engineering," Sol. Energy Eng., vol. 116, no. February, pp. 67-68, 2009.

[36] R. B. D. R. B. Abernethy , R. P. Benedict, “ASME measurement uncertainity.” pp. 161$164,1985$.

[37] R. J. Moffat, "Using uncertainty analysis in the planning of an experiment," J. Fluids Eng. Trans. ASME, vol. 107, no. 2, pp. 173-178, 1985.

[38] L. S. Sundar, M. K. Singh, I. Bidkin, and A. C. M. Sousa, "Experimental investigations in heat transfer and friction factor of magnetic Ni nanofluid flowing in a tube," Int. J. Heat Mass Transf., vol. 70, pp. 224-234, 2014.

[39] J. Xu, T. Sheng, Y. Hu, S. A. Baig, X. Lv, and X. Xu, “Adsorption-dechlorination of 2,4dichlorophenol using two specified MWCNTs-stabilized Pd/Fe nanocomposites," Chem. Eng. J., vol. 219, pp. 162-173, Mar. 2013. 
[40] N. V. Perez-Aguilar, P. E. Diaz-Flores, and J. R. Rangel-Mendez, "The adsorption kinetics of cadmium by three different types of carbon nanotubes," J. Colloid Interface Sci., vol. 364, no. 2, pp. 279-287, Dec. 2011.

[41] B. Pan and B. Xing, "Adsorption mechanisms of organic chemicals on carbon nanotubes," Environ. Sci. Technol., vol. 42, no. 24, pp. 9005-9013, 2008.

[42] H. Wei, S. Deng, Q. Huang, Y. Nie, and B. Wang, "Regenerable granular carbon nanotubes / alumina hybrid adsorbents for diclofenac sodium and carbamazepine removal from aqueous solution," vol. 7, 2013.

[43] C.-Y. Kuo and H.-Y. Lin, "Adsorption of aqueous cadmium (II) onto modified multiwalled carbon nanotubes following microwave/chemical treatment," Desalination, vol. 249, no. 2, pp. 792-796, Dec. 2009.

[44] M. Hadavifar, N. Bahramifar, H. Younesi, and Q. Li, “Adsorption of mercury ions from synthetic and real wastewater aqueous solution by functionalized multi-walled carbon nanotube with both amino and thiolated groups," Chem. Eng. J., vol. 237, pp. 217-228, Feb. 2014.

[45] A. O. Nanocomposite, T. A. Saleh, and V. K. Gupta, "Characterization of the Chemical Bonding between Al 2 O 3 and Nanotube in MWCNT /,” pp. 739-743, 2012.

[46] V. K. Gupta, S. Agarwal, and T. A. Saleh, "Synthesis and characterization of aluminacoated carbon nanotubes and their application for lead removal," J. Hazard. Mater., vol. 185, no. 1, pp. 17-23, 2011.

[47] N. Sankararamakrishnan, M. Jaiswal, and N. Verma, "Composite nanofloral clusters of carbon nanotubes and activated alumina: An efficient sorbent for heavy metal removal," Chem. Eng. J., vol. 235, pp. 1-9, Jan. 2014. 
[48] H. Search, C. Journals, A. Contact, M. Iopscience, and I. P. Address, “Covalent functionalization of carbon nanotubes : synthesis, properties and applications of fluorinated derivatives \{," vol. 705.

[49] X. ju Wang, D. sheng Zhu, and S. yang, "Investigation of pH and SDBS on enhancement of thermal conductivity in nanofluids," Chem. Phys. Lett., vol. 470, no. 1-3, pp. 107-111, 2009.

[50] J. Huang, X. Wang, Q. Long, X. Wen, Y. Zhou, and L. Li, "Influence of pH on the stability characteristics of nanofluids," 2009 Symp. Photonics Optoelectron. SOPO 2009, pp. 1-4, 2009.

[51] M. L. V. Ramires, C. A. Nieto Castro, Y. Nagasaka, A. Nagashima, M. J. Assael, and W. A. Wakeham, "Standard Reference Data for the Thermal Conductivity of Water," J. Phys. Chem. Ref. Data, vol. 24, no. 3, pp. 1377-1381, 1995.

[52] Y. Ding, H. Alias, D. Wen, and R. A. Williams, "Heat transfer of aqueous suspensions of carbon nanotubes (CNT nanofluids)," Int. J. Heat Mass Transf., vol. 49, no. 1-2, pp. 240250, 2006.

[53] N. N. Venkata Sastry, A. Bhunia, T. Sundararajan, and S. K. Das, "Predicting the effective thermal conductivity of carbon nanotube based nanofluids," Nanotechnology, vol. 19, no. $5,2008$.

[54] C. T. Nguyen et al., "Temperature and particle-size dependent viscosity data for waterbased nanofluids - Hysteresis phenomenon," Int. J. Heat Fluid Flow, vol. 28, no. 6, pp. 1492-1506, Dec. 2007.

[55] D. Shin and D. Banerjee, "Specific heat of nanofluids synthesized by dispersing alumina nanoparticles in alkali salt eutectic," Int. J. Heat Mass Transf., vol. 74, pp. 210-214, Jul. 
2014.

[56] S. Vanapalli and H. J. M. ter Brake, “Assessment of thermal conductivity, viscosity and specific heat of nanofluids in single phase laminar internal forced convection," Int. J. Heat Mass Transf., vol. 64, pp. 689-693, Sep. 2013.

[57] I. M. Shahrul, I. M. Mahbubul, S. S. Khaleduzzaman, R. Saidur, and M. F. M. Sabri, “A comparative review on the specific heat of nanofluids for energy perspective," Renew. Sustain. Energy Rev., vol. 38, pp. 88-98, Oct. 2014.

[58] D. A. Vincely and E. Natarajan, "Experimental investigation of the solar FPC performance using graphene oxide nanofluid under forced circulation," Energy Convers. Manag., vol. 117, pp. 1-11, 2016. 